\title{
Rules and Facts on Low-Carbon Technology Diffusion
}

This chapter supplies an in-depth factual understanding of the market-related determinants of low-carbon technology (LCT) diffusion, as well as the relevant developments in the climate and the trade legal regimes to date. In doing so, it facilitates a better understanding of the possible linkages between international trade and LCT diffusion, also the implications of using the Common Concern doctrine in that regard. It begins with a brief, yet illuminating account (Section I) of the origins of technology transfer as a political agenda in the form of early attempts to negotiate a technology transfer code. Following the failure of the code negotiations, the unique expression of technology development and transfer is traced through the evolving, predominantly soft law framework of the climate regime (Section II). It is then joined by a sweeping survey of empirical studies from various sources - to clearly understand and establish the role of markets, and economic instruments in facilitating LCT diffusion (Section III). Against the backdrop of this legal and empirical surveys, the chapter finally indulges into an assessment of the trade rules and practices pertaining to technology development and transfer (Section IV), helpful to later highlight the possible areas of action in the next chapter. Summary analyses appear at the end of each section, which then feed into the conclusion at the end of the chapter. The main contribution of this chapter is in supplying an upto-date and comprehensive regulatory and factual account - useful not only to substantiate later arguments, but also to update the reader on the current developments.

\section{The Origin of the Polemics on Technology Transfer}

Technology transfer originally emerged as a claim made by the developing to the developed countries in the backdrop of the global South's attempts to create a New International Economic Order (NIEO) in the post-world war II era. Although unsuccessful to generate a binding international agreement, it had a lingering impact on the subsequent developments in different legal regimes, where technology transfer retained a contentious character. The origin story of 
technology transfer as a negotiation agenda is educative of the points where states' views mingle and stray.

\section{A Unsuccessful Code Negotiations}

The fundamental basis of the demands for technology transfer made by the newly decolonised and other developing countries emerging from the second world war was based on the premise of economic development being a right, coupled with the understanding that access to modern scientific and technological knowledge is an indispensable component to attain the desired quality of growth. ${ }^{214}$ Therefore, the claim was essentially of fairness, i.e. the developing country firms should be able to access necessary technologies from their developed counterparts on fair terms. The wording of the UN General Assembly Resolution ${ }^{215}$ regarding the NIEO in 1974 followed by a Charter ${ }^{216}$ of Economic Rights and Duties of States reflected this sentiment. For example, Article 13 of the Charter mentioned that "[e]very State has the right to benefit from the advances and development in science and technology for the acceleration of its economic and social development". 217 The same provision also called upon the developed countries to "[...] co-operate with the developing countries in the establishment, strengthening and development of their scientific and technological infrastructures and their scientific research and technological activities so as to help to expand and transform the economies of developing countries.". 218

What made the approach contentious was the perceived difficulty in gaining access to modern technologies. The prevalent business practices were considered as posing obstacles to that end. Under the spotlight were practices like the charging of very high fees for transfers, terms in licensing agreements preventing competition, the practice of packaged transfers, etc. ${ }^{219}$ Moreover, the

214 The reformist agenda, as Roffe and Tesfachew term the period during 196os and 1970s. See, Pedro Roffe and Taffere Tesfachew, 'The Unfinished Agenda' in Surendra J Patel, Pedro Roffe and Abdulqawi Yusuf (eds), International Technology Transfer: The Origins and Aftermath of the United Nations Negotiations on a Draft Code of Conduct (Kluwer Law International 2001).

215 United Nations General Assembly, 'Declaration on the Establishment of a New International Economic Order' (United Nations 1974) Resolution A/RES/3201 (S-VI).

216 United Nations General Assembly, 'Charter of Economic Rights and Duties of States' (United Nations 1974) Resolution A/REs/3281 (XXIX).

217 ibid 13.

218 ibid.

219 Countess P. Jeffries, 'A Preliminary Evaluation of the Proposed Text' in Surendra J Patel, Pedro Roffe and Abdulqawi Yusuf (eds), International Technology Transfer: The Origins and Aftermath of the United Nations Negotiations on a Draft Code of Conduct (Kluwer Law International 2001) 21-24; Dennis Thompson, 'An Overview of the Draft Code' in Surendra 
use of intellectual property rights protections (e.g. patents) by the technology supplier firms to prevent working, wider diffusion, and use of the technology to export products was also perceived as a problem. This fuelled demands for a comprehensive multilateral review of the terms of technology transfer agreements and to develop a set of mutually agreed terms in the form of a code on one hand, and also a revision of the standards of intellectual property protection, especially the Paris Convention on Industrial Property on the other. ${ }^{220}$

With the gift of hindsight, scholars see that the absence of a truly shared goal was a key reason for the failure of the NIEO based claims of technology transfer. ${ }^{221} \mathrm{~A}$ number of developing countries were already experimenting with locally suited technology transfer policies domestically, e.g. the parameters for approved license agreements, reducing scope and duration of patents, domestic working requirements, and provision for compulsory licensing. Whereas the developed countries focused on protecting the business interests, calling for adequate protection of intellectual property rights across the borders and also a liberal regulatory environment for businesses and foreign investment. Due primarily to this absence of a shared vision, the Code negotiations that started in 1972 backed by the UNCTAD, failed in 1983 after six conferences. ${ }^{222}$

The failed Code negotiation nevertheless served to clarify the position of the parties. It also portrayed how the issue of technology transfer can spill over from the domain of private contractual transactions to that of inter-state claims. The developing countries sought to use their advantage in numbers to correct a perceived systemic disadvantage to their private firms. Whereas the developed countries refused to influence private sector transactions by regulating the market. All sides nevertheless agreed that transfer of technology comprised mostly of private business transactions, taking place in the

J Patel, Pedro Roffe and Abdulqawi Yusuf (eds), International Technology Transfer: The Origins and Aftermath of the United Nations Negotiations on a Draft Code of Conduct (Kluwer Law International 2001) 6o-64.

220 Wei Zhuang, Intellectual Property Rights and Climate Change: Interpreting the TRIPS Agreement for Environmentally Sound Technologies (Cambridge University Press 2017) 47-59.

221 Roffe and Tesfachew (n 214); Padmashree Gehl Sampath and Pedro Roffe, 'Unpacking the International Technology Transfer Debate: Fifty Years and Beyond' (2012) 36 ICTSD, Issue Paper $<$ http://papers.ssrn.com/sol_3/papers.cfm?abstract_id=2268529> accessed 25 October 2020.

222 It should be noted that in the same period, the technology transfer based approach towards deep seabed mining also failed, as the United States refused to ratify the UN Law of the Sea Convention and forced a revision of the rules on that issue. For details, see Thomas Cottier, Equitable Principles of Maritime Boundary Delimitation: The Quest for Distributive Justice in International Law (Cambridge University Press 2015) 54-57. 
backdrop of a domestic and international legal framework. One could see that transfer of technology became a political agenda due to the dissatisfaction over the operation of private commercial transactions. It also failed because of disagreements on that point. The tussle between these two competing views for a dominant narrative position at the international level has coloured the nature and approach of the subsequent legal regimes tackling technology transfer, especially the World Trade Organization (WTO) and the multilateral environmental agreements (MEA s). ${ }^{223}$

\section{B Regime Specific Trends}

Since the failure of the Code negotiations, the issue of technology transfer, instead of remaining as a self-standing agenda, was subsumed as a component in different issue-specific negotiations (e.g. trade regulation, or protection of the environment). This dispersion of the notion across supra-national forums of varying institutional set-up and strength resulted in a perceptible difference in the way the notion was understood, incorporated, and implemented. The most notable is the divergence in the approach towards operationalisation of technology transfer in the subsequent MEA s vis a vis the multilateral trade regime embodied in the wTo.

Provisions for technological and financial assistance are ubiquitous in the soft laws, as well as the treaty instruments regarding environmental issues that came into being in the decades following the United Nations Conference on Human Environment in 1972. ${ }^{224}$ A typical example can be Article 10A of the Montreal Protocol on Ozone Depleting Substances. The provision holds that

Each Party shall take every practicable step, consistent with the programmes supported by the financial mechanism, to ensure:

(a) that the best available, environmentally safe substitutes and related technologies are expeditiously transferred to Parties operating under paragraph 1 of Article 5; and

223 Laurence Boisson de Chazournes, 'Technical and Financial Assistance' in Daniel Bodansky, Jutta Brunnée and Ellen Hey (eds), The Oxford Handbook of International Environmental Law (First edition, Oxford University Press 2007).

22428 multilateral agreements were identified by the UNCTAD in 2001 as containing technology transfer arrangements. All except 9 on that list were multilateral environmental agreements; the rest being intellectual property conventions, WTO covered agreements and the Energy Charter Treaty. See, UNCTAD (ed), Compendium of International arrangements on Transfer of Technology: Selected Instruments (United Nations 2001). 
(b) That the transfers referred to in subparagraph (a) occur under fair and most favourable conditions. ${ }^{225}$

About the same time, in the then newly established wто, ${ }^{226}$ specific mention of technology transfer as an obligation appeared in the context of intellectual property issues. The wто Agreement on the Trade-Related Aspects of Intellectual Property Rights (TRIPS) 227 was the outcome of efforts by the developed countries to ensure for their businesses an avenue to secure protection of intellectual property rights (IPR) abroad. The agreement provided for mandatory minimum standards of IPR protection for all the WTO members minus the least-developed countries (LDC s) to establish and maintain. The agreement was founded on the conviction that the protection of intellectual property rights "should contribute to the promotion of technological innovation and to the transfer and dissemination of technology $[. .$.$] ". { }^{228}$ Moreover, the developed countries were put under a strict obligation to incentivise respective institutions to transfer technologies to the LDC members. ${ }^{229}$

The differences between the trade and the environmental treaty regimes' approach to technology transfer manifest how political interests vary across those regimes, thereby influencing the final bargain struck. In the MEA s, the scope of technology transfer was narrow and specific to the issue at hand. Therefore, the North $\mathrm{v}$ South schism over property rights did not dominate the discussions. ${ }^{230}$ Moreover, the emergence of integrative notions like sustainable development helped to move the narrative of technology transfer closer towards preservation of commons. The developed countries also found it politically palatable to commit additional financial resources to issues that were of interest to their own citizens. ${ }^{231}$ As a result, the practice of finance backed technology transfer provisions became standardised in the MEA s. This

225 Article 10A, Montreal Protocol on Substances that Deplete the Ozone Layer $1987(1522$ UNTS 3; 26 ILM 1550 (1987)).

226 Marrakesh Agreement Establishing the World Trade Organization 1994 (1867 UNTS 154; 33 ILM 1144 (1994)).

227 Agreement on Trade-Related Aspects of Intellectual Property Rights 1994 (Marrakesh Agreement Establishing the World Trade Organization, Annex 1C, 1869 UnTS 299; 33 ILM 1197 (1994)).

228 Article 7, ibid.

229 Article 66.2, ibid. For further details, see section IV B below.

230 Abdulqawi A Yusuf, 'Technology Transfer in the Global Environmental Agreements: A New Twist to the North-South Debate' in Surendra J Patel, Pedro Roffe and Abdulqawi Yusuf (eds), International Technology Transfer: The Origins and Aftermath of the United Nations Negotiations on a Draft Code of Conduct (Kluwer Law International 2001) 315.

231 de Chazournes (n 223) 957-958. 
approach prioritised making of state-to-state financial and technical assistance to attain the MEAs targets instead of constraining the firms' freedom to contract. $^{232}$

In contrast, the WTO rules were a branch of international economic law that sought to regulate international trade between its members in unprecedented detail and depth. These new set of rules played a significant part in influencing the terms of competition among private firms. In that context, the TRIPS agreement made sure that holders of intellectual property are provided with a minimum level of security in all jurisdictions. This Agreement triggered the code-era conflict of interests in the wTо, in a slightly different formulation. The question became whether rigorous protection of, or flexibilities regarding IPR s would contribute to transfer of technology. While mandatory technology transfer had no place in the wTO agreement, one exception was the strict obligation to transfer technology to the LDC s.

This brief account explains how the absence of a shared understanding of the meaning and determinants of technology transfer resulted in the notion's regime-specific and somewhat kaleidoscopic character. Although the same state-level actors animated the transfer of technology agenda in various regime settings, differences between those regime characteristics and specific political interests of the parties greatly influenced how the key issues were perceived and pursued. To further comprehend the implications of this 'structural ambiguity'233 that is diffusion of LCT, we explore the evolution of the notion in the relevant treaty regimes, namely those of climate change and international trade.

\section{Developments in the Climate Regime}

The legal regime of climate change shares common traits with other MEAs. Bodansky and others highlight three key characteristics of the climate treaty regime. First and foremost, the regime undergoes a soft law based incremental evolution. ${ }^{234}$ This is observable in the framework and Protocol approach to the rulemaking, gradual institutionalisation, and standard setting through diverse bodies managed through the Conferences of Parties (COP). ${ }^{235}$ The second trait is that the rules are framed in a fashion that eases participation. ${ }^{236}$

\footnotetext{
232 Yusuf (n 230) 314, 317.

233 We recall the term coined by Humphreys mentioned earlier. See Humphreys (n 9o).

234 Bodansky, Brunnée and Rajamani (n 129) 22-26.

235 ibid 22-26, 56-6o.

236 ibid 61-64.
} 
It is evidenced in the practice of shallow initial commitments across a wide range of issues, ${ }^{237}$ coupled with a mechanism for progression over time. Participation is further eased by according flexibilities in terms of commitment, ${ }^{238}$ also by differentiated standards of treatment. ${ }^{239}$ The last feature, another consequence of the soft approach, is that compliance mechanisms related to the regime are mostly non-adversarial and facilitative in nature. ${ }^{240}$

The evolution of the arrangements related to technology development and transfer in the climate regime also manifest the above features. As shown below, the institutional blueprint of technology transfer has emerged through work done at the committee stages, thereupon endorsed by successive COPs. There are also continuous efforts to develop a closely twined relationship between technology transfer and the financial support mechanisms. In addition, parallel areas have also emerged with a potential positive influence on low-carbon technology diffusion. These areas include mitigation mechanisms like the market-based approaches, especially the clean development mechanism (CDM), as well as the non-binding commitment processes like the Nationally-determined commitments (NDCs).

A

Evolution of Institutional Frameworks

Provisions relating to technology transfer in the framework convention were, true to the title, of framework nature. To bridge the wide divergence between the developing and developed parties' views, ${ }^{241}$ the language of the relevant UNFCCC provisions are vague. ${ }^{242}$ The convention lays down a commitment (Article 4.1) upon all members to "promote and cooperate in the development, application, diffusion, including transfer, of technologies."243

237 Daniel Bodansky, The Art and Craft of International Environmental Law (Harvard University Press 2010) 183-187.

238 Recall Article 4.2 of the Paris Agreement, urging that "[e]ach Party shall prepare, communicate and maintain successive nationally determined contributions that it intends to achieve". Flexibility is also unavoidable as the operational rules are formulated at institutional levels that do not have the mandate to negotiate treaty provisions.

239 Bodansky, Brunnée and Rajamani (n 129) 26-27.

240 ibid 64-68. The Paris Agreement relies upon periodic review in the form of global stocktake (Article 14), and a compliance mechanism (Article 15) that is "expert-based and facilitative in nature and function in a manner that is transparent, non-adversarial and non-punitive".

241 While the developing countries claimed for access to technology on easier terms, possibility of issuing compulsory license and to obtain financial support; the developed nations wanted technology 'cooperation' rather than 'transfer', see, ibid 140-141.

242 ibid 140.

243 Article 4.1(c), United Nations Framework Convention on Climate Change (n 14). 
Implementation of that obligation is differentiated, as the developed countries are put under a strict obligation of conduct. Article 4.5 urges the developed parties to "take all practicable steps" to "promote, facilitate and finance" transfer of technologies to other parties, particularly the developing ones. The same essence is also traceable in Article 4.3, which further obliges the developed countries to provide financial support for, inter alia, transfer of technology. ${ }^{244}$ In contrast, the efforts to be made by developing countries to implement their respective commitments under the convention were made conditional upon reception of financial support and technology transfer. ${ }^{245}$ While being unable to indicate practical avenues to implement those commitments, the language of the framework convention already highlighted key issues that would recurrently guide the evolution of the institutional process, namely differentiation, and support. Also, these are the only provisions that are grounded in hard law

Subsequently, the Kyoto Protocol entering into force in 2005, did not contribute much in developing frameworks for technology transfer. As is well known, the language of strict differentiated obligation introduced by the Protocol contributed to its slow demise, as the top emitters gradually abandoned the process. ${ }^{246}$ In the same spirit of the Framework Convention, the Kyoto Protocol obliged all parties to cooperate to create effective modalities of technology transfer. ${ }^{247}$ It also strengthened the language of urging the developed parties to extend financial support for the transfer of technology to the developing parties. ${ }^{248}$ Although unrelated to the formal institutional framework related to technology transfer, the market based mechanisms established under the Protocol, especially the clean development mechanism (CDM), had some technology transfer effect. ${ }^{249}$ Nevertheless, for reasons explained later in this chapter, those mechanisms also gave rise to controversies yet to be settled among the participants. ${ }^{250}$ Operation of the Kyoto Protocol is extended till 2020 with respect to parties willing to commit thereunder.

\footnotetext{
244 Article 4.3, ibid.

245 Article 4.7 , ibid.

246 Bodansky, Brunnée and Rajamani (n 129) 105-108; Bodansky, The Art and Craft of International Environmental Law (n 237) 161-162, 185; Rosen (n 161); Napoli (n 161).

247 Article 10(c), Kyoto Protocol to the United Nations Framework Convention on Climate Change 1998 (UN Doc FCCC/CP/1997/7/Add1; 37 ILM 22 (1998)).

248 Article 11(2)(b), ibid.

249 See pp. 71 \& 84 below.

250 See pp. 72-73 below.
} 

Structural Development at the Conference of Parties (COP s) The real development of the institutional arrangements for technology transfer took place at the cop level, where efforts have been complex, and multipronged. Very early on (COP4), Parties agreed to implement Article 4.5 of the UNFCCC through need-based financing of technology transfer projects ${ }^{251}$ with support from the finance arm of the convention. The result was the initiation of the technology needs assessment process (TNA) (Box 1). This process was purposed to provide developing countries with a clear understanding of their technology needs and priorities. ${ }^{252}$ Also in COP 4, the Subsidiary Body on Scientific and Technological Advice (SBSTA) was mandated to initiate a consultative process for effective implementation of Article 4.5 of the Convention. ${ }^{253}$ By 2001, the first regulatory framework was launched with supervision from an expert group, of which the key details are provided in the following sub-section.

\section{Box 1: Technology Needs Assessments (TNA s) ${ }^{254}$}

Initiated in 2001, the TNAs have arguably become the most important step that a developing country can undertake to specify its technology needs and obtain necessary support thereupon. Undertaken voluntarily by a developing country member to the UNFCCC, a TNA paves the path to adopt a Technology Action Plan (TAP), which then serves as a basis to develop bankable technology transfer projects.

The TNA process remains loosely linked to the evolving technologyrelated institutional framework of the climate regime. Currently, the technology executive committee (TEC) discharges guidance and overview functions regarding the TNA, a task previously conducted by the now demised expert group on technology transfer (EGTT). However, the bulk of the activities, i.e. initiation, technical support, advice, and later finance, are carried out by a number of collaborators.

While implementation of the TNA projects have always been in the domain of the Global Environment Facility (GEF), the key finance arm

251 Decision 2/CP4, 'Report of the Conference of the Parties on Its Fourth Session' (1998) FCCC/ CP/1998/16/Add.1. At that period, the sole financing arm was the Global Environment Facility (GEF). For more on the GEF, see pp 67-69 below.

252 'TNA History' <http://unfccc.int/ttclear/tna/history.html> accessed 25 October 2020.

253 Decision 4/CP4, 'Report of the Conference of the Parties on Its Fourth Session' (n 251); Decision 9/CP5, 'Report of the Conference of the Parties on Its Fifth Session' (1999) FCCC/ CP/1999/6/Add.1.

254 'TNA History' (n 252). 
of the UNFCCC; the assessment activity was initially assisted by the UN Environment Programme (UNEP) and the UN Development Programme (UNDP). From 2009, TNAs and implementation thereof were carried out as a global project in phases. Finance was still supplied by the GEF under a strategic technology transfer programme, implementation was carried out by the UNEP in partnership with the Danish Technical University (DTU).

So far, there has been three TNA global project phases, which have seen to 85 countries undergoing the assessment. According to the official technology information repository 'tt:clear', while about 26o mitigation project has been floated by developing countries for finance, about 6 so far have been supported. Linked to the TNA s, the GEF also launched 14 pilot projects, which remain at different stages of completion.

\section{a) Technology Transfer Framework (TTF)}

The technology transfer framework (TTF), adopted in 2001 (COP7), was the result of a consultative process. ${ }^{255}$ The TTF envisaged activities around five key themes, namely (i) technology needs assessments (TNA s), (ii) technology information; (iii) enabling environments; (iv) capacity building; and (v) mechanisms for technology transfer. The needs assessment, already an ongoing process, was integrated with the framework with a view to identifying and prioritising the areas of support required by the developing countries. Actual transfers were planned to be attained in two ways- creation of an enabling regulatory environment on one hand, and the developing countries' technological capacity building on the other. This would remain a rare instance when regulatory reform, especially fair-trade policies would find mention in connection with enabling environment in a COP document on technology transfer. Elaborating the tasks under that theme, the developed parties were urged to " [...] promote further and to implement facilitative measures, for example, export credit programmes and tax preferences, and regulations, as appropriate, to promote the transfer of environmentally sound technologies". ${ }^{256}$ Equal emphasis, if not more, was put on capacity building efforts for the developing countries, along with an urge to make greater financial resources available for the same. ${ }^{257} \mathrm{The}$

\footnotetext{
255 Decision 4/CP7, 'Report of the Conference of the Parties on Its Seventh Session' (2001) FCCC $/ \mathrm{CP} / 2001 / 13 /$ Add.1.

256 Annex to the Decision 4/CP7, ibid 26-27.

257 Annex to the Decision 4/CP7, ibid 27-29.
} 
dual emphasis on enabling environment and capacity building would become the balancing act for all subsequent technology transfer arrangements.

The institutional mechanism that emerged out of the TTF was in the form of an Expert Group on Technology Transfer (EGTT). The EGTT was mandated to boost stakeholder coordination, cooperation, and to facilitate the development of relevant projects and programs. The goal behind creating an 'expert' group was probably to depoliticise the issues and to work towards objective solutions. Although the group played some facilitative function, ${ }^{258}$ it was criticised to be a weak one, having a top-down approach towards technology transfer. It also failed to defuse the tensions between the developed and the developing countries' views. ${ }^{259}$ The mandate of the expert group lapsed in 2010.

\section{b) The Technology Mechanism (TM)}

Work began in 2007 to replace the TTF with a new framework. The Bali Action Plan, which was instrumental in initiating the new process, flagged enhanced action on technology transfer and provision of related finance as two key components of a long-term climate deal. ${ }^{260}$ Pursuant to that, the informal Copenhagen Accord decided in 2009 to establish a bottom-up 'technology mechanism' (TM). The decision was formalised in the following year at COP16. ${ }^{261}$ Composed of a policy and an implementation arm (technology executive committee (TEC) and climate technology centre and network (CTCN), respectively), the Tм was proposed to build upon the previous activities, albeit with redefined priorities and operational structures, as explained below. ${ }^{262}$

The policy arm of the mechanism, i.e. the TEC, is composed of a body of twenty independent technology experts from the developed and the developing countries. ${ }^{263}$ The functions assigned to the TEC was mostly deliberative and advisory, including, inter alia, making recommendations on technology transfer barriers. ${ }^{264}$ Compared to the EGTT, the TEC had a reduced scope, as

258 Efforts included training and capacity building to carry out technology needs assessments. Merylyn Hedger, 'Stagnation or Regeneration: Technology Transfer in the United Nations Framework Convention on Climate Change (UNFCCC)' in David Ockwell and Alexandra Mallett (eds), Low-carbon technology transfer: from rhetoric to reality (Routledge 2012) 213.

259 de Coninck and Sagar (n 89) 26o.

26o Bali Action Plan, Decision 1/CP13, 'Report of the Conference of the Parties on Its Thirteenth Session' (2007) FCCC/CP/2007/6/Add.1 4-5.

261 Decision 1/CP16, 'Report of the Conference of the Parties on Its Sixteenth Session' (2010) FCCC/ CP/2010/7/Add.1 <http://unfccc.int/resource/docs/2010/cop16/eng/o7ao1.pdf> accessed 25 October 2020.

262 ibid $18-22$.

263 ibid 3 o.

264 ibid 19-20. 
some of the issues like capacity building and availability of necessary financial resources were moved to different fora. Based on the assigned mandate, inputs from public, private and institutional stakeholders, and periodic guidance from the COP s, work in the TEC progressed based on a rolling agenda. Such work mostly included different thematic dialogues, workshops, periodic analysis, and guidance support to TNAs.

It is important to note that perception of the kind of steps necessary to be taken for the development of enabling environments for technology transfer changed with the shift from the earlier framework. Between 2012 and 2015, activities undertaken by the TEC touching upon enabling environments and barriers to technology transfers can be summed up to a workshop on national systems of innovation in developing countries, ${ }^{265}$ thematic dialogues, and some periodic recommendations made to the COP. ${ }^{266}$ It shows that the earlier emphasis on the need for specifically addressing trade-related issues has waned. A plausible reason for this can be the Parties' different positions on market-based approaches to mitigation. In addition, the absence of jurisdiction to discuss trade matters can also be a factor. Among other mandated tasks, the TEC supplied guidance to the TNA process over time. ${ }^{267}$ Even in that regard, as we would see later in this chapter, Secretariat reports suggested the significance of barriers that can be tackled by trade policy measures. ${ }^{268} \mathrm{De}-$ spite that, there were no such discussions or recommendations from the TEC. The body, however, made suggestions to develop a permanent linkage with the financial mechanisms

The Climate Technology Centre and Network (СтCN), the other integral part of the TM, is comprised of a central coordinating body connected to a worldwide network of member organisations. Together, the CTCN responds to the needs of technical assistance (TA) submitted by the developing countries. The CTCN is hosted by a UNEP-led consortium and is financed from a variety of sources, ranging from donor countries, the finance mechanism of the convention, as well as contributsions from consortium members. The type of

\footnotetext{
265 It was held in 2014. 'Joint Annual Report of the Technology Executive Committee and the Climate Technology Centre and Network for 2014' (2014) FCCC/sB/2014/3 $8<$ http:// unfccc.int/resource/docs/2014/sb/eng/o3.pdf> accessed 25 October 2020.

266 'Joint Annual Report of the Technology Executive Committee and the Climate Technology Centre and Network for 2015' (2015) FCCC/sB/2015/1 12-13 <http://unfccc.int/resource/ docs $/ 2015 / \mathrm{sb} / \mathrm{eng} /$ o1.pdf $>$ accessed 25 October 2020 .

267 ibid 10-11; 'Joint Annual Report of the Technology Executive Committee and the Climate Technology Centre and Network for 2016' (2016) FCCC/sB/2016/1 9-10 <http://unfccc.int/ resource/docs/2016/sb/eng/o1.pdf> accessed 25 October 2020.

268 Synthesis reports on technology needs are discussed in pp. 85-87 below.
} 
technical support provided by the CTCN is request-based, occasionally involving assistance regarding TNAS. The CTCN website reports that so far $180 \mathrm{TA}$ requests have been received, of which 77 have been completed. ${ }^{269}$

The success of the work undertaken by the TEC and СTCN remained closely linked to the availability of adequate financial resources. This is a persistent problem for the network, frequently resulting in its inability to prioritise the support projects. ${ }^{270}$ Despite having a finance-backed approach to the transfer of technology, availability of resources to a tune that is adequate to reach the necessary scale of assistance has never become a reality in the context of the TM. This remains a major handicap for the system.

\section{Technology Framework under the Paris Agreement}

Despite being appended as Annex to the COP21 decision, the Paris Agreement can be considered as a treaty from a legal viewpoint. ${ }^{271}$ Article 10 of the Paris Agreement, coupled with the relevant parts ${ }^{272}$ of the COP21 decision, supply new guidance to the existing technology transfer rules and practices. The new provisions bring adaptation and mitigation activities into equal focus. ${ }^{273}$ Apart from that, the Agreement's provisions further underscores the need for linkage between the technology and financial mechanisms. In somewhat ambiguous wording, the Article also supplies one of the rare instances of strict differentiation in the Paris Agreement, holding that additional financial support "shall be provided to the developing country parties". ${ }^{274}$ As mentioned, the wording

269 'Request Visualizations' (Climate Technology Centre \& Network, 20 August 2015) <https:// www.ctc-n.org/technical-assistance/request-visualizations $>$ accessed 25 October 2020.

270 'Joint Annual Report of the Technology Executive Committee and the Climate Technology Centre and Network for 2018' (2018) FCCC/sB/2018/2 18-21 <https:/unfccc.int/sites/ default/files/resource/SB_2018_2.pdf > accessed 25 October 202O. It is mentioned that the CTCN 'continues to experience challenges related to the availability of sufficient and sustained funding as it strives to fund its activities in future years'.

271 Daniel Bodansky, 'The Legal Character of the Paris Agreement' (2016) 25 Review of European, Comparative \& International Environmental Law 142, 144-145. Of course it opens the question of priority between the terms of the Paris Agreement and the UNFCCC. Nevertheless, between two sets of relatively flexible commitments, conflict is not immediately apparent. For an alternate view arguing the legal form of the Paris Agreement as a Protocol, see Sandrine Maljean-Dubois, Thomas Spencer and Matthieu Wemaere, "The Legal Form of the Paris Climate Agreement: A Comprehensive Assessment of Options' (2015) 9 Carbon \& Climate Law Review 68.

272 Adoption of the Paris Agreement 2015 (Report of the Conference of the Parties in its twenty-first session, Decision 1/CP 21, FCCC/CP/2015/10/Add1) paras 66-71.

273 Articles 10(1) and 10(2), Paris Agreement (n 28).

274 Article 1o(6), ibid. 
is ambiguous as it does not clarify who bears that responsibility to extend financial support.

Article 10 also envisioned a new technology framework (TF) that would serve the long-term vision of the Paris Agreement. ${ }^{275}$ While the institutional framework of the TM is subsumed into the Paris process, the TF is supposed to provide overarching guidance to the former. The corresponding part of the COP21 decision entrusted the SBSTA with the development of the particulars of technology framework along four themes - (i) undertaking and updating of the TNAs, (ii) provision of enhanced financial support for the TNAs, (iii) assessments of technologies ready to transfer, and (iv) enhancement of enabling environments and removal of barriers. ${ }^{276}$ This task was discharged by December 2018, when in COP24 the details of the framework (i.e. the 'Paris Rulebook') were agreed. ${ }^{277}$

The TF envisages five focused areas of action, namely: innovation, implementation, enabling environment and capacity building, collaboration and stakeholder engagement, and support. In many ways, it seems to have successfully picked up the avenues of action, which did not have a strong voice in the technology mechanism and incorporated them to create a long-term, comprehensive work agenda. With respect to trade and diffusion of LCT, the re-introduced theme of enabling environment and also that of collaboration is of special importance.

With respect to creating an enabling environment, the $\mathrm{TF}$ holds that it is important to consider the challenges faced by the countries, as well as their different needs. Learning from the decades of insight from conducting TNAs, the activities suggested by the framework to create and enhance enabling environment include, inter alia, the following:

(b) Facilitating countries in enhancing an investment-friendly environment, [...] a policy environment, legal and regulatory frameworks and other institutional arrangements; [...

275 Article 10(4) reads as, "[a] technology framework is hereby established to provide overarching guidance to the work of the Technology Mechanism in promoting and facilitating enhanced action on technology development and transfer in order to support the implementation of this Agreement [...]'. ibid.

276 Paragraphs 66-71, Adoption of the Paris Agreement (n 272) 9-10; de Coninck and Sagar (n 89).

277 Technology framework under Article 10, paragraph 4, of the Paris Agreement 2019 (Meeting of the Parties to the Paris Agreement on the third part of its first session, Decision 15/CMA1, Annex, FCCC/PA/CMA/2018/3/Add2). 
(d) Assisting countries in developing and implementing policies for enabling environments to incentivize the private and public sector to fully realize the development and transfer of climate technologies;

(e) Assisting governments in playing a key role in fostering private sector involvement by designing and implementing policies, regulations and standards that create enabling environments and favourable market conditions for climate technologies; ${ }^{278}$

Yet again, it is submitted that such tasks as mentioned above cannot be executed without the involvement of the trade regulations. However, it is worthwhile to hope that the framework holds collaboration with, and engagement of stakeholders at the local, regional, national, and global levels to be important. It has been mentioned that the necessary action in this regard, inter alia, is:

Enhancing collaboration and synergy with relevant international organizations, institutions and initiatives, [...] to leverage their specific expertise, experience, knowledge and information, particularly on new and innovative technologies; ${ }^{279}$

In sum, it would appear that the TF indicates the existence of a shared will to tackle, among others, economic and market-related barriers to technology development and transfer. To that effect, collaboration with other organisations and institutions are also foreseen. While any effective collaboration is yet to develop, this is a potential opening to establish formal linkages with the trade legal regime to explore policy measures that assist low-carbon technology diffusion. We return to this issue in the following chapter.

At least three compliance enabling mechanisms are linked to the post-Paris arrangement for the transfer of low-carbon technologies. A periodic review will look into the effectiveness of the тм in implementing the agreement, as well as the adequacy of the support provided to the mechanism. ${ }^{280}$ The extent to which the mechanism adapts its work to the guidance of the technology framework is a factor in the assessment of effectiveness. ${ }^{281}$ Moreover, under a novel transparency framework, the developed country parties are required to

278 ibid 16.

279 ibid $20(d)$.

280 Adoption of the Paris Agreement (n 272) para 69.

281 Scope of and modalities for the periodic assessment referred to in paragraph 69 of decision 1/CP.21 2019 (Meeting of the Parties to the Paris Agreement on the third part of its first session, Decision 16/CMA1, Annex, FCCC/PA/CMA/2018/3/Add2) para 2(k). 
furnish, among others, information on the technology and capacity-building support provided to the developing countries. ${ }^{282}$ Information so provided remains subject to a technical expert review. Lastly, the process of 'global stocktake'283 is also required to take note of the efforts in terms of support provided to the developing country Parties with respect to technology development and transfer. ${ }^{284}$ Characteristic to the emphasis upon non-adversariality that epitomizes the Paris Agreement, none of these avenues provides options for strict enforcement when the necessary level of technology transfer is wanting.

\section{B Evolution of Financial Support Systems}

The account of the institutional evolution of technology transfer arrangements already showcases the importance of adequate finance to bankroll the transfer projects as well as related technical assistance. This entails footing a financial bill of unprecedented scale, actual measurement of which can vary depending on the assumed scope of technologies. For example, the SDG Goal 13 calls for annual contribution of USD 100 billion by 2020 through a fully operationalised Global Climate Fund. ${ }^{285}$ One earlier study endorsed by the expert group on technology transfer (EGTT) concluded that development, diffusion, and deployment of mitigation technologies may require annual additional finance of USD 262 to 670 billion. ${ }^{286}$ To date, reaching such levels have remained impossible.

The key finance mechanisms of the climate regime, i.e. the Global Environment Facility (GEF), and the new Green Climate Fund (GCF) allocate resources for technology transfer activities at different stages. The aforementioned study finds that out of the overall flow of finance in 2009 for development and diffusion of climate technologies that stood somewhere between 69 to 153 billion US dollars, only 19 million passed through the GEF that was spent in supporting developing countries. ${ }^{287}$ Establishment of a permanent linkage with the

282 Article 13, Paris Agreement ( $\mathrm{n}$ 28); Modalities, procedures and guidelines for the transparency framework for action and support referred to in Article 13 of the Paris Agreement 2019 (Meeting of the Parties to the Paris Agreement on the third part of its first session, Decision 18/CMA1, Annex, FCCC/PA/CMA/2018/3/Add2) para 126.

283 Articles 10(6) and 14, Paris Agreement (n 28).

284 Matters relating to Article 14 of the Paris Agreement and paragraphs 99-101 of decision 1/CP.21 2019 (Meeting of the Parties to the Paris Agreement on the third part of its first session, Decision 19/CMA1, FCCC/PA/CMA/2018/3/Add2) para 36(f).

285 Goal 13, United Nations General Assembly (n 210).

286 EGTT, 'Recommendations on Future Financing Options for Enhancing the Development, Deployment, Diffusion and Transfer of Technologies under the Convention' (2009) FCCC/SB/2009/2 $24<$ http://unfccc.int/resource/docs/2009/sb/eng/o2.pdf> accessed 25 October $202 \mathrm{O}$.

287 ibid 20. 
financial mechanism remains an open issue, as described below. Following paragraphs provide a brief overview of the situation of technology finance so far. $^{288}$

\section{The Global Environment Facility (GEF)}

The GEF is a consortium of international agencies, countries and civil societies that support and finance implementation activities under several MEAs, including the UNFCCC. ${ }^{289}$ It uses periodically replenished contributions made by the participants. With respect to technology development and transfer to tackle climate change, the operational focus of the GEF until 2007 was on removing the market obstacles preventing diffusion of mature technology and supporting development and deployment of promising technologies. ${ }^{290}$ In response to the parties' request in $2007,{ }^{291}$ the GEF presented a new strategic program the year after, named Poznan strategy, which still guides the actions of the institution. ${ }^{292}$ In light of that strategy, technology finance operation of the GEF takes place under three prongs, namely (i) providing assistance in undertaking of the TNA s, (ii) implementation of pilot projects arising out of those assessments, and (iii) dissemination of the experiences of success. ${ }^{293}$ Later, after the launch of the technology mechanism (TM), two additional priorities were added to the previous agenda - (i) support to the CTCN, and (ii) public-private partnerships for technology transfer. ${ }^{294}$

Through the Poznan Strategic Program, the GEF has been continuously supporting the technology activities, though the scale of overall support can be put to question. Regarding the TNAs, a total of eighty-four countries were

288 For additional information on the scale and importance of public financial commitments, see Chapter 5 I at p. 198 onwards.

289 As per decision 12/CP2 at COP2, a memorandum of understanding was struck between the UNFCCC COP and the Council of GEF.

290 GEF, 'Transfer of Environmentally Sound Technologies: Case Studies from G E F Climate Change Portfolio' 3-4 <http://www.thegef.org/sites/default/files/publications/GEFTechTransfer-lowres_final_2.pdf> accessed 25 October. For a critical take on GEF's market transformation approach, see the studies by Watson \& Byrne, and Haum in page 83 and 84 respectively below.

291 Decision 4/CP13, 'Report of the Conference of the Parties on Its Thirteenth Session' (n 26o) $26-28$.

292 Decision 2/CP14, 'Report of the Conference of the Parties on Its Fourteenth Session' (2009) FCCC/CP/2008/7 3-4 <https://unfccc.int/resource/docs/2008/cop14/eng/o7.pdf> accessed 25 October 2020.

293 GEF, Implementing the Poznan Strategic and Long-Term Programs on Technology Transfer (2012) $5^{-6 .}$

294 ibid 6. 
provided GEF support in three phases since 2001. Out of those, thirty-six TNAs are completed, twenty-eight underway and twenty about to begin. ${ }^{295}$ During this period, only eleven pilot projects arising out of the TNAs have been approved for implementation. ${ }^{296}$ Support to the CTCN is provided by the GEF under five ongoing projects. All these add up to nineteen mitigation technology transfer projects (including three cancelled ones) in totoal since 2009, requiring the entity to invest 111.7 million USD of own fund and 709.3 million of co-financing by other institutions. ${ }^{297}$ The facility identifies the key perceived obstacles in financing technology projects as - (i) absence of domestic policy frameworks enabling the adoption of EST s, (ii) absence of robust technology options, (iii) information unavailability, (iv) lack of viable business and delivery models to supply the markets, and (v) lack of finance. ${ }^{298}$

The Green Climate Fund (GCF)

Parallel to the Poznan Strategic Program, the Copenhagen Accord in 2009 floated the idea of a new finance mechanism in the form of the Green Climate Fund (GCF), which was eventually launched in 2010 at the COP 16 in Cancun. The new fund is a response to the voiced demand for new and additional finance to tackle climate change. Like the GEF, the GCF is also an operational entity under the finance mechanism of the Framework Convention, but unlike the former, it deals solely with the climate change issue. Despite having an informal target to mobilise USD1oo billion annually and initiate a 'paradigm shift' in low-carbon development, the GCF has been successful in collecting about USD 10.3 in actual pledges so far. ${ }^{299}$ As of July 2019, the fund has approved a total of 111 projects in total deploying USD 5.2 billion of its own resources, and triggering another USD 1.5 billion in co-finance. ${ }^{300}$ By the same time, the GCF received eleven finance request from the CTCN,

\footnotetext{
295 UNFCCC, 'Report of the Global Environment Facility to the Conference of the Parties' (2017) FCCC/CP/2017/7 47-49 <http://unfccc.int/resource/docs/2017/cop23/eng/o7.pdf> accessed 25 October 2020.

296 ibid 46-47.

297 ibid 44.

298 ibid 103-109; Global Environment Facility, 'Report of the Global Environment Facility on the Progress Made in Carrying out the Poznan Strategic Programme on Technology Transfer' (2018) 122-136.

299 Green Climate Fund, 'Eighth Report of the Green Climate Fund to the Conference of the Parties to the United Nations Framework Convention on Climate Change' (2019) FCCC/ $\mathrm{CP} / 2019 / 34^{-5}$.

300 ibid $12-13$.
} 
of which only six has been approved, amounting to total commitment USD 1.8 million. ${ }^{301}$ While there may be some technology transfer benefit arising from the overall GCF engagement, but a system to track such achievement is still in process. ${ }^{302}$

(iii) The Linkage between Technology and Finance

There is no doubt that the level of success of a finance-driven international support mechanism for technology transfer would largely be a function of the amount of resources allocated for the purpose. Current legal arrangements still underperform on this account, as featured by technology transfer being only a partial responsibility in the GEF agenda. While the developing countries demand establishment of a hard linkage between the finance (including the GCF) and the technology mechanism (TM), it was consistently being resisted by the developed countries. ${ }^{303}$ In 2015 , the COP 21 invited the TEC and the operating entities of the finance mechanism (namely the GEF, and the GCF) to sit together and find ways of supporting the TM. ${ }^{304} \mathrm{In}$ COP22, the parties encouraged the GCF to regularly report the actions being taken to establish the linkage. Later in COP23, an independent review recommended formalisation of the relationships between CTCN, GEF, and GCF through enhanced collaboration of the national focal points of these entities (nationally designated authorities (NDA) for GCF, and nationally designated entities (NDE) for CTCN). ${ }^{305}$ The latest reports reveal that the CTCN is partnering with the GCF to access some funds from that latter entity's 'readiness program' ${ }^{306}$ However, partnership with the GEF still remains on an ad hoc basis. ${ }^{307}$ In the absence of a stronger, and supporting relationship between technology support and finance, the success of the TM would remain a far cry. ${ }^{308}$

\footnotetext{
301 ibid 18-19.

302 ibid 19.

303 de Coninck and Sagar (n 89) 263.

304 Decision 13/CP.21 'Report of the Conference of the Parties on Its Twenty-First Session' (2015) FCCC /CP/2015/10/Add.2 28-29.

305 'Report of the Independent Review of the Effective Implementation of the Climate Technology Centre and Network' (2017) FCCC/CP/2017/3 para 9o.

306 'Joint Annual Report of the Technology Executive Committee and the Climate Technology Centre and Network for 2019' (2019) FCCC/sB/2019/4 para 104; Green Climate Fund (n 299) para 97.

307 ibid para 105 .

308 de Coninck and Sagar (n 89) 275 .
} 
C Other Avenues Contributing to Low-Carbon Technology Diffusion

(i) Market-Based Approaches

a) The Clean Development Mechanism (CDM)

While the technology transfer arrangements were too slow to take shape, the market-based mitigation measures agreed under the Kyoto Protocol ${ }^{309}$ of the Framework Convention, especially the clean development mechanism (CDM), ${ }^{310}$ became an unlikely vehicle for low-carbon technology transfer. It is unlikely because the mandate of the CDM was never related to technology. Opening in 1998, the Kyoto Protocol had the objective of strengthening the mitigation commitments of the UNFCCC parties. To that effect, it provided for strict emission reduction targets, which were possible to be met through domestic, as well as extraterritorial mitigation activities. The latter was known as market-based mitigation measures, comprising of joint implementation, with or without emission trading schemes, ${ }^{311}$ and the CDM.

The CDM has a project-centred approach. According to the Kyoto Protocol, entities from the developed countries can invest in mitigation projects in the developing countries and get credit (i.e. certified emission reduction, or CER) for emission reductions that is 'additional' to 'business as usual'. A project developer, with approval from the host country, initially submits the documents for approval. A project is approved when it is registered by the Executive Board (Ев) of the CDM. When successfully implemented, the ев issues the CERS, which can then be bought and sold in the market and used by any Annex I party to prove their compliance with the Kyoto limits during the commitment period. 312

Although studies have shown some limited success and untapped potential of CDM projects to transfer low-carbon technologies, ${ }^{313}$ some drawbacks have been pointed out as well. The CDM approach was primarily mandated

309 Kyoto Protocol to the United Nations Framework Convention on Climate Change 1997.

310 Article 12, ibid.

311 Article 4(6), ibid.

312 Joëlle de Sépibus, 'Reforming the Clean Development Mechanism to Accelerate Technology Transfer' (2009) NCCR Trade Working Paper 2009/42 6 <https://www.wti.org/ research/publications/7/reforming-the-clean-development-mechanism-to-acceleratetechnology-transfer/> accessed 25 October 2020 .

313 Eric Haites and others, 'Technology Transfer and the Clean Development Mechanism (CDM)' in David Ockwell and Alexandra Mallett (eds), Low-carbon technology transfer : from rhetoric to reality (Routledge 2012); Stephen Seres, Eric Haites and Kevin Murphy, 'Analysis of the Contribution of the Clean Development Mechanism to Technology' (UNFCCC 2010) <https://cdm.unfccc.int/Reference/Reports/TTreport/TTrep1o.pdf> accessed 25 October 2020 . 
to mitigate emissions, not to transfer technology. As a result, the project designs were suited to the needs of the former and not the later. It also became clear that the structure and design of the CDM approval, and issue of CER $S$ were flawed. Moreover, the projects tended to concentrate on only a number of destinations - as private entrepreneurs were reluctant to move elsewhere. De Sepibus identified some of these failures as being: (i) the problem of fixing the emission accounting baseline, (ii) private intervention in auditing, (iii) technology path dependency, (iv) chilling effect on developing country low-carbon policy development, etc. ${ }^{314}$

Along with the rest of the Kyoto Protocol, operation of the CDMs is projected to last till 2020 (i.e. the second commitment period, 2013-20). As it is official that the Protocol would not be extended further, and an alternate plan is underway as the Paris Agreement, the current iteration of CDM would expire after that period. While some were positive about market-based mitigation options like the CDM, the others held deep concerns about its overall impact and reforms. ${ }^{315}$ The conflicting views have influenced the negotiation under the Paris Agreement, as shown below.

b)

Difficulty to Renew Market-based Approaches under the Paris Agreement

In an attempt to address all the divergent views surrounding the market-based approaches to mitigation, Article 6 of the Paris Agreement was drafted in a language that covers and encourages all forms of possible cooperation activities. ${ }^{316}$ While creating the opportunity for market-based cooperative mechanisms for emission mitigation, it also underscores the need for ensuring overall emission reduction, stringent accounting, strong oversight, distributional support to adaptation, and contribution to sustainable development. Side by side, it also recognises the need to coordinate and cooperate on mitigation towards the fulfilment of NDC s through non-market approaches. The language of the provision does not, however, indicate any potential technology transfer benefit arising out of such cooperation activities.

The market-based cooperative approaches under the Paris Agreement could further be divided into two types. The internationally transferred mitigation outcomes (ITMO s) possibly envisage transactions like emission trading or other

\footnotetext{
314 de Sépibus (n 312) 10-13.

315 Andrew Howard, 'Voluntary Cooperation (Article 6)' in Daniel Klein and others (eds), The Paris Agreement on Climate Change: Analysis and Commentary (Oxford University Press 2017) 182.

316 Article 6.1, Paris Agreement (n 28).
} 
forms of credit transaction processes ${ }^{317}$ subject to the requirement that they promote sustainable development, are transparent, and ensure environmental integrity. ${ }^{318}$ Further guidance was sought to be supplied by the SBSTA as part of the Paris rulebook. ${ }^{319}$ Article 6.4 to 6.7 lay down further details of a new mechanism, which in broad parts resembles CDM or Joint Implementation (JI) approaches under the Kyoto system. The language of the whole Article avoids using terms like 'credit', 'market' or 'trade' - a result of the strong aversion of certain members. ${ }^{320}$ The elaborated mechanism urges ensuring overall mitigation of global emission, support of adaptation activities from the proceeds and avoiding double counting.

Details of the mechanism were left to be developed in the rulebook. ${ }^{321}$ By the first session of the conference of parties serving as a meeting of the parties to the Paris Agreement (CMA) in 2018, no consensus on any of these issues has been reached. Key disagreements are regarding methods to avoid double counting of emissions, decision on carrying over Kyoto era CDM credits, means of ensuring overall mitigation reduction, and difficulty to account for trade in mitigation outcomes between parties with varying NDC commitments. ${ }^{322}$ Recently concluded COP25 / CMA2 also failed to find an agreement, and the issues have been pushed to the next conference in 2020 .

a)

\section{Technology Aspects of Other Climate Processes}

Nationally determined contributions (NDC), the foremost building blocks of aggregate mitigation under the Paris process, bear a deep connection with the availability and access to low-carbon technologies. According to a UNFCCC secretariat study, ${ }^{323}$ almost all of the developing countries (140) refer to

317 Howard (n 315) 185-186; Andrei Marcu, Carbon Market Provisions in the Paris Agreement (Article 6) (Centre for European Policy Studies (CEPS) 2016) 5-7.

318 Articles 6.2 and 6.3, Paris Agreement (n 28).

319 'Report of the Conference of the Parties on Its Twenty-First Session' (n 304) para 37.

320 Marcu (n 317) 7; Howard (n 315) 188.

321 'Report of the Conference of the Parties on Its Twenty-First Session' (n 304) 38-39. It should however be noted that while INDC s are an iterative process, TNA s are so far a oneoff step leading a technology action plan.

322 See for details, 'In-Depth Q\&A: How "Article 6" Carbon Markets Could "Make or Break" the Paris Agreement' (Carbon Brief, 29 November 2019) <https://www.carbonbrief. org/in-depth-q-and-a-how-Article-6-carbon-markets-could-make-or-break-the-parisagreement> accessed 25 October 2020 .

323 UNFCCC, 'INDCs and Technology: A Synthesis of Technology Issues Contained in Intended Nationally Determined Contributions' (2016) <https://unfccc.int/ttclear/misc /StaticFiles/gnwoerk_static/HOME_infobox_2/a61fgf4b94704dd78fo6b2bc7cdob547/ f7bbe982812a469db476fd4917714813.pdf> accessed 25 October $202 \mathrm{O}$. 
technologies in the NDC s. $70 \%$ of all the non-Annex I parties seek international technology development and transfer support to implement their NDC commitments. ${ }^{324}$ While the technology mechanism was not frequently referred to, the developing country parties indicated financial as well as non-financial obstacles as barriers to attaining the NDC commitments. In 2018, the technology executive committee (TEC) suggested to use the TNA process to specify, prioritise and update over time the technology aspects of the NDC s. ${ }^{325}$

b) Nationally Appropriate Mitigation Actions (NAMAS) ${ }^{326}$

Similarly, nationally appropriate mitigation actions (NAMAs) were an outcome of an earlier process that is still in place. NAMAs share characteristics with NDC s as well as the TNA s. They were made with a view to creating a transparent platform for mitigation projects. While the UNFCCC hosts a registry for the NAMA s prepared and submitted for finance, there is no institutional finance that is allocated for the projects. A donor-supported NAMA facility finances the projects. Many of the NAMA s actually involve introduction of new technologies to a specific domestic emission sector. However, in comparison to the number of NAMA s submitted, very little (about 8.5\%) have been financed for implementation..$^{327}$

\section{Summary Analysis}

This section summarises the key points emerging from the above discussion.

a) Balancing and Supporting Function of Technology Transfer

Effective legal arrangements for technology transfer remains an indispensable part of a long-term global climate deal. Not only does it enable countries to increase the level and scale of emission mitigation, technology transfer, especially providing assistance to the developing countries in that regard, also performs a crucial balancing function. Overall, such arrangement is a key avenue

\footnotetext{
324 ibid 2.

325 Technology Executive Committee (TEC), 'Updated Paper on Linkages between the TNA and NDC Process' (UNFCCC 2018) TEC/2018/16/7 19-20 <https://unfccc.int/ttclear/misc /StaticFiles/gnwoerk_static/tn_meetings/40o67a6o235c4bic9737egabf532003a/e8aobdogbec44237934ee7ed569b2d9d.pdf> accessed 25 October 2020 .

326 To be clear, the NAMA here does not have any realation with the non-agricultural market access negotiation at the WTO.

327 Angelica Afanador and others, Status Report on Nationally Appropriate Mitigation Actions (NAMAs) (Katja Eisbrenner, Noémie Klein and Xander van Tilburg eds, ECN, ECOFYS 2017).
} 
to implement the ideal of common but differential responsibility in practice. It also enables fostering of inclusivity in the multilateral climate agreement by ensuring the greatest number of participation.

\section{b) Institutional Evolution is Soft-Law Based, Incremental, and Facilitative}

We find that much of the development of the institutional frameworks regarding technology development and transfer in the climate regime has taken place incrementally, using soft-law based approaches. ${ }^{328}$ The upside of such an approach is that the resultant frameworks are inclusive in terms of participants, as well as coverage of interests. However, encompassing different interests and approaches result in systems that are complex and difficult to navigate. This is true for the whole of the Paris Agreement. ${ }^{329}$ Also, inclusivity comes at the cost of sacrificing legal stringency of the substantive commitments. As the latest experiences with the Paris Agreement, and the technology framework therein show, aspirational goals and some procedural obligations form the core of the operative rule, emphasising more on a highly participatory and facilitative nature of progress. ${ }^{330}$ It is yet to be seen whether such frameworks result in generating effective and adequate levels of technology transfer.

c)

One-Off Projects, the Thrust of Current Actions, Are Inadequately Financed

In practice, under the current arrangements, the developing countries obtain necessary low-carbon technologies through implementation of standalone projects - e.g. following up a TNA, ${ }^{331}$ through CDM s, ${ }^{332}$ or by obtaining finance for the submitted NAMA. ${ }^{333}$ These processes are only loosely connected to the current legal framework for technology transfer in the sense that the bulk of the work is carried out by autonomous entities (e.g. GEF for project implementation, and the UNEP-DTU consortium for TNA s). These processes are only effective to the extent financial resources are committed to them. Given the slow pace of growth of the scale and volume of institutional finance channelled to

328 Hedger correctly termed the evolution of a working technology transfer process under the UNFCCC as 'slow, laborious and incremental'. Hedger (n 258).

329 Brunnée, 'The Rule of International (Environmental) Law and Complex Problems' (n 200).

330 Jutta Brunnée, 'MEAs and Complex Prevention' (Hague Winter Academy, Hague, January 2019) [on file with the author].

331 See Box 1 at p. 6o above.

332 See p. 71 above.

333 See p. 74 above. 
low-carbon technology diffusion, it is only realistic to conclude that exclusive dependence on finance backed technology transfer would be unsuccessful to bring forth the kind of systemic technological change that has been showed to be necessary to avoid climate change.

\section{d) Systemic Change Would Require Finding New Ways to Enhance Technology Diffusion}

Following the above conclusion, i.e. the inadequacy of financial support, it is important that other complementary avenues of progress are explored. Of key importance are the market-based reform approaches including necessary revision of international trade and investment practices. Experience so far would suggest that although market-based approaches are not alien to the climate regime, they tend to be controversial as their benefits remain limited and execution questionable. The difficulty to deal with it within the climate law framework can arise due to several factors - (i) trade-related issues are subject to the regulatory jurisdiction of the WTO, ${ }^{334}$ (ii) this may not be in the interest of all parties, as experience suggests that developed countries prefer market-based approaches, (iii) in terms of impact however, some of these issues may affect developing country process and production, and lastly (iv) there has been some negative experience with such mechanisms under the Kyoto Protocol. Given these factors, it is highly welcome that the enabling environment and capacity building feature prominently in the new technology framework as an integrated agenda. ${ }^{335}$

To throw a clearer light on the contours of the task at hand, the next section undertakes a comprehensive overview of the objective understanding of the barriers to the diffusion of LCT $\mathrm{s}$.

This section serves as a synopsis of the current empirical understanding of the barriers to low-carbon technology diffusion that bear a potential linkage with trade rules. It presents the picture that is emerging from the scholarly literature, especially since the late 20oos. This includes - (i) studies that specifically focused on counting and analysing climate technology patents, (ii) those that focus on finding a broader range of barriers in a specific sector, or economy,

334 This is discussed at length from p. 8o onwards. This also forms the crux of Chapter 3.

335 See pp. 65-66 above. 
and (iii) the self-assessed barriers to prioritised mitigation technologies, as communicated by the developing countries.

All the studies commonly point out the prevalence of economic and financial challenges to low-carbon technology diffusion. The scope of the available research, however, remain scant both in terms of the sectoral coverage, as well as the number of countries studied. Drawing general conclusions therefrom can be informative, but not highly accurate. However, there is a higher probability for new and more comprehensive empirical analyses to rather corroborate than differ with the insights that are currently available and presented hereunder.

\section{A Studies on the Relevance of Intellectual Property Rights}

Traditionally, the debate on patent flexibility vs protection grabs the most attention when it comes to the issue of trade and technology transfer barriers. This debate often ends with split discourse of development vs diffusion. ${ }^{336}$ The developing countries tend to draw from their experience with IPR $s$ in the field of public health protection, and conclude that easing of IPR $s$ would facilitate access to climate technologies. ${ }^{337}$ Whereas, opposite views held by most developed countries indicate the innovation encouraging role of the IPR s through the promise of secured exploitation and the possibility of eventual disclosure.

One of the earliest studies looking at global patenting activities was done by Dechezleprêtre and others. ${ }^{338}$ The authors examined thirteen environmental technologies to locate the places of innovation and the role played by the developing countries, also to measure the extent of technology transfer. It was found that between 1978 and 2005, patenting activities in the studied areas were highly concentrated (90\%) in twelve mostly OECD member countries. ${ }^{339}$ With respect to the number of patents registered, developing countries were

336 David G Ockwell and others, 'Intellectual Property Rights and Low Carbon Technology Transfer: Conflicting Discourses of Diffusion and Development' (2010) 20 Global Environmental Change 729.

337 See for example, Frederick M Abbott, Innovation and Technology Transfer to Address Climate Change: Lessons from the Global Debate on Intellectual Property and Public Health (ICTSD International Centre for Trade and Sustainable Development 2009); Ahmed Abdel-Latif, 'Intellectual Property Rights and the Transfer of Climate Change Technologies: Issues, Challenges, and Way Forward' (2015) 15 Climate Policy 103, 106, 112.

338 Antoine Dechezleprêtre and others, 'Invention and Transfer of Climate ChangeMitigation Technologies: A Global Analysis' (2011) 5 Review of Environmental Economics and Policy 109.

339 Namely (in order from top), Japan, US, Germany, China, South Korea, Russia, Australia, France, UK, Canada, Brazil and Netherlands. The ranking changes with Germany on the lead if only high value patents are counted. 
found to be lagging far behind. ${ }^{340}$ The study concluded, among others, that the domestic policy environment, as well as the price of fossil fuel influence patenting activities. Another key finding, later corroborated by other researchers was a spike in clean technology patenting from the 199os. This was attributed to the growing number of international environmental regulation. Considering the gathered data on multiple filing of a patent application as a proxy of technology transfer, the study also concluded that such transfers took place largely within OECD countries, followed by $22 \%$ of transfers from the OECD to non-OECD countries, mainly China. Transfers between developing countries remained close to none $(1 \%)$.

In a similar method, Lee et al. examined the patent landscape, concentration of IP, relationships between technology systems and policy implications thereof. ${ }^{341}$ Focused on patenting activities in six low-carbon energy technologies $^{342}$ spanning from 1976 to 2007 , the study confirmed the similar surge in patenting during the 199os. In addition to the OECD countries, the authors named China as an important innovation hub. It was due to the growing Chinese market since the early 20oos, attracting foreign investments and increased patent filing by their subsidiaries. The authors concluded that patent protection in the studied sector is not a hindrance to technology access as the patent ownerships did not result in the holders' monopolistic dominance in the market. Instead of multiple filing, Lee and others looked at co-assignment of patents as a proxy for the evidence of collaboration and hence technology diffusion. It was found most such activities took place within and between the OECD countries (95\%), demonstrating synergistic relationships between firms, universities, and public research bodies.

Clean technology diffusion has been in the focus of the Global Challenges Reports periodically published by the World Intellectual Property Organization (WIPO). As a part of that, Helm and others replicated the abovementioned research by Lee et al. with a longer range of data (till 2011) on four of the six selected technologies. ${ }^{343}$ It was found that that over the last five years of the period studied, there has been an immense growth in the number of patent

340 Taiwan in 21st, India in 27th and Mexico in 29th position. Dechezleprêtre and others (n 338) 116.

341 Bernice Lee, Ilian Iliev and Felix Preston, Who Owns Our Low Carbon Future?: Intellectual Property and Energy Technologies (Chatham House 2009).

342 Wind, solar PV, concentrated solar power, biomass-to-electricity, carbon capture, and cleaner coal.

343 Sarah Helm, Quentin Tannock and Ilian Iliev, 'Renewable Energy Technology: Evolution and Policy Implications - Evidence from Patent Literature' (WIPO 2014) Global Challenges Report. The sectors authors looked at were biofuels, solar thermal, solar PV, and wind. 
filings in the selected technologies. ${ }^{344}$ Also, in certain cases, specific technologies (e.g. solar PV) outgrew other competitors within the sector. A novel finding was that of the growth of developing country firms. In three of the four selected technologies, the authors noted the position of China as the leading patent family owner, contributed by the public research institutions and universities. ${ }^{345}$ Especially in the solar PV sector, the authors found the technological front runners to be based in Asia. ${ }^{346}$

The 2015 WIPo Global Challenges Report, authored by Lybecker and Lohse, focused on the role of intellectual property and other factors enabling the diffusion of green technologies. ${ }^{347}$ Based on a survey of secondary literature, the authors concluded that "[w]ell-developed systems to protect and enforce IP rights have been found to stimulate technology diffusion." ${ }^{348}$ One work was however mentioned, which finds protection of IPRs resulting in rising costs of green technologies. ${ }^{349}$ The authors also highlight a range of market and behavioural failures that slow the rate of diffusion of green technologies. ${ }^{350}$ The market failures identified therein are energy market failures, ${ }^{351}$ capital market failures, ${ }^{352}$ innovation market failures, ${ }^{353}$ and information problems ${ }^{354}$.

An extensive study of the changing landscape of patents in clean energy technologies (СЕT) ${ }^{355}$ was jointly undertaken by the United Nations Environment Program (UNEP), the European Patent Office (EPO), and the International

\section{4 ibid 4.}

345 ibid 34 .

346 It is due to the growing dominant presence of South Korean (e.g. LG) and Indian (e.g. Suzlon) firms. ibid 22, 26, 32 .

347 Kristina M Lybecker and Sebastian Lohse, 'Innovation and Diffusion of Green Technologies' (WIPO 2015) Global Challenges Report <http://www.wipo.int/edocs/pubdocs/en/wipo_rep_gc_2015_1.pdf> accessed 25 October 2020 .

348 ibid 10-12.

349 Global Commission on the economy and climate, Better Growth, Better Climate: The New Climate Economy Report: The Global Report (2014) 261-262.

$35^{\circ}$ Lybecker and Lohse (n 347) 16. The structure was adapted from an earlier work, see Gillingham and Sweeney (n 82).

351 Energy market failure includes causes such as untamed environmental externalities, average-cost electricity pricing, and lack of energy security. ibid.

$35^{2}$ Capital market failure is caused by liquidity constraints. ibid.

353 It arises from the lack of an innovator's ability to prevent R\&D spillovers. ibid.

354 This includes information asymmetry, lack of information, principal-agent problem etc. ibid.

355 Fifty technology categories (including renewable technologies like solar PV, wind turbine, geo thermal, and components like rotors and blades) were considered by the EPO within the scope of the term 'clean energy technology'. 
Centre for Trade and Sustainable Development (ICTSD). ${ }^{356}$ The study again confirmed the fact of patent concentration in the OECD countries, as most of the applications were also found to be coming from a few key jurisdictions. ${ }^{357}$ However, when the proportion of CET patents to the overall patenting activity in a location (i.e. relative importance given to CET) is considered, developing countries like Brazil, India, and Mexico come closer to the top in select sectors.

Noting that the data of multiple patent filing is an unsuitable proxy for technology transfer, ${ }^{358}$ the abovementioned study undertook a licensing survey to unearth the factors that influence technology owners' tendency towards out-licensing and collaboration. The results indicate that firms that are intensively involved in the CET sectors engage in collaborative IP activities more frequently than other firms. ${ }^{359}$ However, very few of such activities involve outlicensing to developing countries. ${ }^{360}$ Even where such involvement exists, the partner firm is most often located in China, Brazil, India, or Russia. ${ }^{361}$ A survey conducted among the firm managers revealed that key perceived out-licensing obstacles include transaction costs, difficulty in finding partners, and difficulty in finding mutually agreeable terms of license (e.g. pricing, and geographic scope). ${ }^{362}$ It was also found that while robust domestic laws on intellectual property protection in the partner country would indeed be a considered factor, it is never the sole determinant of a firm's decision to out-license. ${ }^{363}$ Other influencing factors were found to be the presence of scientific capability on the technology receiving side, market conditions, and investment climate.

A study by Copenhagen Economics focused specifically on whether IPRs pose a barrier to climate technology transfer. The answer was negative because it was found that there was no significant price difference between patented and free technologies. ${ }^{364}$ The study further tended to argue that IP R s cannot be a significant problem to technology transfer in low-income countries simply

356 UNEP, EPO and ICTSD, 'Patents and Clean Energy: Bridging the Gap between Evidence and Policy' (UNEP, EPO, ICTSD 2O10).

357 Namely the USA, Japan, Germany, the UK and France, and the Republic of Korea.

$35^{8}$ It is because of the fact that firms apply for patent protection in a specific jurisdiction not only to work it therein, but also for defensive purposes.

359 UNEP, EPO and ICTSD (n 356) $55^{6-57 .}$

36 o ibid $5^{8-59}$.

361 ibid 58 .

362 ibid 59 .

363 ibid.

364 Copenhagen Economics and The IPR Company, 'Are IPR a Barrier to the Transfer of Climate Change Technology?' (2009) 16-17 <https://www.copenhageneconomics.com/ dyn/resources/Publication/publicationPDF/7/27/o/Are_IPR_a_barrier_to_the_transfer_ of_climate_change_technology.pdf $>$ accessed 25 October 2020 . 
because those technologies are hardly ever patented in those regions. ${ }^{365}$ In contrast, absence of domestic IPR protection regulation, lack of absorptive capacity, and subsidies counterproductive to the climate protection goal were indicated as areas that may persist to prevent technology transfer. ${ }^{366}$

\section{B Sector and Country-Focused Studies}

Besides the above, other studies look at low-carbon technology diffusion with respect to specific geographies (mostly China, or India), sectors (e.g. wind, or solar PV based electricity production), or projects (e.g. GEF financed CDM projects). Instead of zeroing in on IPR related concerns, these analyses deal with the opportunities and challenges faced by the private sector operators. They are, as a result, informative of a broader spectrum of hurdles on the path of clean technology adoption.

Barton looked at the relationship between the protection of IPR S and access to clean energy technologies (CET s) in three sectors (solar PV, biomass, and wind). ${ }^{367}$ Studying the level of industry concentration ${ }^{368}$ in these sectors, he finds that those are mostly clustered in developed countries with the exception of some emerging developing country firms mainly in India (wind), China (solar PV), and Brazil. The conclusion drawn therefrom was that the industries in the studied sectors currently operate in an oligopolistic fashion with very little IP R related barrier to entry. ${ }^{369}$ As competition drives the prices of technologies down quickly, entrant firms from the developing countries do not face insurmountable barriers to entry, except for few instances concerning access to state of the art technologies. ${ }^{370}$ Barton, however, draws attention to other industry-specific hindrances, e.g. the protected markets of agricultural produce hurting the biofuel industry. Domestic favouritism in allocating public research funds also breeds inefficiency, according to the author. To make the

365 ibid 15-38. Abdel-Latif cautions against drawing such simplistic conclusions.; Abdel-Latif (n 337) 113 .

366 Copenhagen Economics and The IPR Company (n 364) 27-33.

367 John H Barton, Intellectual Property and Access to Clean Energy Technologies in Developing Countries (ICTSD 2007) <https://seors.unfccc.int/applications/seors/attachments/get_

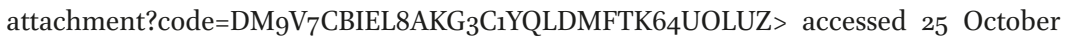
2020.

368 Measured by number of shipments made in case of Solar PV, percentage of national production capacity owned in case of Biomass, and percentage of global market share in case of Wind. Data used are collected from secondary sources.

369 Barton $\left(\mathrm{n}_{367}\right)_{4-5}$. Barton is also one of the first to reject the argument for patent flexibility in clean energy, based upon a drawn parallel with the public health sector.

370 ibid 16. 
renewables competitive, Barton advocated for subsidies, designed and implemented in a non-discriminatory fashion.

Lewis made a comparative analysis in the same year between two successful wind energy firms based in developing countries, i.e. Suzlon in India and Goldwind in China. The goal was to look at how the respective national policy contexts have influenced the firms' technology acquisition and assimilation strategies. ${ }^{371}$ The study shows that globally successful firms can emerge in developing countries even without needing IPR related flexibilities. Lewis highlights that corporations devise strategies to get the most benefit from the enabling policy frameworks put in place by domestic governments. In the Indian context, key policy enablers for Suzlon consisted of progressive central and regional sourcing commitments, feed-in-tariffs, tax breaks, and certification schemes to ensure the quality of the components. Whereas in China, Goldwind benefitted from a progressive national target for generating renewable energy. The Chinese firms were guaranteed long-term prices if they satisfied the local content requirement. ${ }^{372}$ They were also granted research subsidies. ${ }^{373}$ Both firms initially depended on licensing with smaller developed country firms to acquire necessary technologies. Subsequently Goldwind capitalised on the growing domestic market, while Suzlon strategically established itself in key supply markets (e.g. USA), and innovation centres (e.g. Germany and the Netherlands), while benefitting from cheaper manufacturing in India at the same time.

Two field studies on clean technology were reported in a volume edited by Ockwell and Mallett on low-carbon technology transfer. ${ }^{374}$ One conducted by $\mathrm{Pal}$ and Sethi followed the uptake of energy-efficiency technology by Indian SME $s$ in two sectors, i.e. glass foundry, and iron casting. ${ }^{375}$ They found that those SME s suffer from high transaction costs, as well as from deficiencies in expertise, knowledge, and information to take up new technologies. The case the authors followed was one where a domestic knowledge institution acted as a conduit between international technology and the SME s. Access to

371 Joanna I Lewis, 'Technology Acquisition and Innovation in the Developing World: Wind Turbine Development in China and India' (2007) 42 Studies in Comparative International Development 208.

372 It should be noted that such an approach is in clear violation of current wTo rules regulating subsidies.

373 Lewis (n 371) 217-219.

374 Ockwell and Mallett ( $\left.\mathrm{n}_{54}\right)$.

375 Prosanto Pal and Girish Sethi, 'Case Study: Technology Transfer of Energy-Efficient Technologies among Small and Medium Sized Enterprises in India' in David Ockwell and Alexandra Mallett (eds), Low-carbon technology transfer: from rhetoric to reality (Routledge 2012). 
long-term and flexible funding was also provided to the businesses. The technologies in question were adapted to the local need and then implemented throughout the industry.

Watson and Byrne reported the other study, dealing with both mature ${ }^{376}$ and novel ${ }^{377}$ technologies in China. They found a positive effect of government intervention in the market. The researchers concluded that transfer of the mature technologies was made possible due to an incremental policy push by the government over long-term, also at the same time adequate finance options being made available (GEF for boilers, CDM for cement). Acquisition of relevant technologies by the Chinese firms also took place through joint ventures, license agreements with international smEs, and R\&D base acquisitions. Although local firms have acquired significant technological expertise in mature technologies, they still depended on international licenses. Unlike the Indian example above, the Chinese firms often preferred domestic technological solutions over the imported ones due to better access to know-how, and adaptability benefits. Technologies at or closer to the knowledge frontier nevertheless were difficult to gain access to due to non-cooperation by the original owners who are wary of the competition. With respect to the latest generation gas turbine technology for integrated gasification combined cycle (IGCC) power plants, lack of technical skills and access to the technology was found to be key problems. With respect to hybrid electric vehicles (HEV s), lack of government policy backing, and absence of necessary supporting infrastructure were key obstacles.

Gallagher brought her long experience into play when looking at the evolution of four specific technologies ${ }^{378}$ in the expanding Chinese clean energy sector. ${ }^{379}$ With respect to concerns regarding intellectual property thefts, the author found very little evidence of actual patent infringement on CET s. ${ }^{380}$ Based on interviews, patent analysis and examination of domestic dispute settlement practices, Gallagher concluded that the established foreign operators in China take calculated risks and strategically manage their operations for twofold rewards - (i) better access to the Chinese domestic market, and (ii) overall export competitiveness. ${ }^{381}$ Protection of intellectual property was found to be concerns for both foreign and domestic firms in China. But none

376 Efficient boilers, and cement production technologies.

377 Offshore wind power generation, hybrid electric vehicles (HEV), integrated gasification and combined cycle (IGCC) technologies.

378 These are gas turbines, solar Pv, advanced batteries for vehicles, and coal gasification technologies.

379 Gallagher ( $\left.\mathrm{n}_{71}\right)$. See in particular Chapters 3, 4 and 7 of that volume.

380 ibid 110-114.

381 ibid 130-132. 
were so significant as to disrupt the growth of an industry. The most significant issue that calls for intervention is, according to Gallagher, the lack of a 'natural' market with a growing demand for CET s. ${ }^{382}$ This led the author to put the principal focus on 'market formation policies' for further improvement. ${ }^{383}$ Market formation policies epitomise "stable, predictable, transparent and medium to long-term" policies that help build broad and sustained markets by tackling pervasive externalities and distortions. ${ }^{384}$

Haites and others analysed the CDM projects that referred to technology transfer in the project documents to find out the significant determinants of transfer in their specific context. ${ }^{385}$ Apart from finding a declining rate of technology transfer to the recipient countries over time, ${ }^{386}$ the authors further discover a positive relationship between the level of technology transfer and project size. ${ }^{387}$ Moreover, technology transfer declines if the same country has several projects of the same type. ${ }^{388}$ Although the study itself does not report any conclusive findings regarding barriers to transfer, a similar study done by the same authors for the UNFCCC in 2010 presented a counter-intuitive conclusion that countries facing economic or intellectual property rights related barriers experience more technology transfers through the CDM. ${ }^{389}$ The authors' conjecture on the possible reason of such finding is that the financial security of the CDM projects may attract to the host country technologies that would otherwise not be introduced by the private entities. ${ }^{390}$

Haum studied an off-grid solar PV project implemented in India, to assess the role of the GEF finance in the development of technological capacity. ${ }^{391}$ The study was based on the premise that technology transfer through market transformation should only be considered successful if it resulted in the

\footnotetext{
382 ibid $74-77$.

383 ibid 96-101, 167-173.

384 ibid $96-97,171-172$.

385 Haites and others (n 313).

386 This is due to the fact that once a technology is introduced in the recipient country, it loses novelty for the purpose of analysis. Also given the fact that CDM projects tended to concentrate in a few countries, such decline should be reasonably expected.

387 Haites and others (n 313) $175^{-179 .}$

388 ibid.

389 Seres, Haites and Murphy (n 313) 18, 22.

390 ibid 22, 50.

391 The Photovoltaic Market Transformation Initiative (PVMTI) is one of the earliest GEF financed market transformation projects. See, Ruediger Haum, 'Project-Based Market Transformation in Developing Countries and International Technology Transfer: The Case of Globel Environment Facility and Solar Photovoltaics' in David Ockwell and Alexandra Mallett (eds), Low-carbon technology transfer : from rhetoric to reality (Routledge 2012).
} 
incremental development of the capacity to innovate among recipients. ${ }^{392}$ For the new innovative capacity to come out, it was also important that there is steady demand for the technology in the market. Haum found out that the studied project resulted in some new demands for off-grid solar home systems, but the scale or the quality thereof was not adequate for the domestic cell and module manufacturers to further develop their technological capacity. One qualified conclusion drawn by the author is that for market transformation to work as envisaged by the GEF, the size of the market intervention has to be large enough to create incentives at a scale attractive for the domestic manufacturers, which is currently not the case. Haum also indicated a positive influence of the domestic market size, and size of the relevant economic sector on technology transfer, as the suppliers are more interested to cater to bigger markets.

\section{Technology Barriers Perceived by Developing Countries}

Technology needs assessments (TNAs) ${ }^{393}$ provide an outlook of the barriers faced by the developing countries in adopting, inter alia, prioritised mitigation technologies. As of yet, around eighty-five countries have completed the TNA process. Three synthesis reports, ${ }^{394}$ published by the UNFCCC secretariat since 2006, allow an aggregate overview of eighty countries. ${ }^{395}$ The summary reports describe, among others, the type of mitigation technologies prioritised as necessary by the participating non-Annex I countries, the key barriers in deployment and diffusion of the same, as well as the possible measures necessary to remove such obstacles.

Barrier analysis in the submitted TNA s largely follow the categorisation of barriers in the related guidebooks. ${ }^{396}$ The TNA guidebook on barrier analysis indicates that barriers to technology transfer can be classified in ten categories, which are - (i) economic and financial, (ii) market failures, (iii) policy, legal and regulatory, (iv) network failures, (v) institutional and organizational capacity, (vi) human skills, (vii) social, cultural and behavioural, (viii) information and awareness, (ix) technical, and (x) others. ${ }^{397}$ The information box (Box

392 ibid 187-19o.

393 For a brief description, see Box 1 at p. 6 o above.

394 The first published in 2006, the second and the third in 2009 and in 2013 respectively.

395 The second report, which expanded upon the first one focused on all the TNA s until that date, being 70 in total. The third TNA synthesis report was prepared in response to the SBSTA request to provide a summary of the TNA s completed under the Poznan strategic program. Out of the 31 TNA s included there, 10 were from countries which were not available in the second report. All add up to 80.

396 See, for example, Boldt and others (n 55) $15^{-25}$.

397 ibid $17-18$. 
2) below provides an illustrative account of individual non-Annex I members' perception of technology transfer barriers.

A key insight emerging from the synthesis reports is that the need to tackle economic and market-related barriers is perceived as most significant by almost all the parties. The second report showed that this category of barriers was mentioned by most $(82 \%)$ of the countries with regard to prioritised mitigation technologies. ${ }^{398}$ The third report assigned more than 90\% of the responses to this category. ${ }^{399}$ Economic and market-related barriers include problems such as high cost of the technologies, related affordability problem, and the availability of cheaper but more polluting alternatives, the difficulty of finding finance due to the lack of interest shown by the private sectors (e.g. banks and other financiers), underdeveloped markets, irregularity of supply, etc. ${ }^{400}$ Energy technologies, the sector most prioritised by the parties regarding mitigation, also suffered from the same barriers. ${ }^{401}$ Apart from economic barriers, the next big obstacles were categorised as policy and regulatory barriers, and technical barriers. ${ }^{402}$ The technical barrier category deserves attention, as problems within that category, e.g. the inadequacy of appropriate standards, codes, and certification are particularly related to the WTO rules. ${ }^{403}$ Other repeated mentions included lack of human capacity and state resources, shortage of information on appropriate technologies, the complexity of new technologies, institutional capacity shortage, etc. ${ }^{404}$ Among the measures highlighted by countries for removal of the barriers included, inter alia, state involvement in attracting foreign investment, gaining access to different international and national funding sources, rationalising prices and removal of unreasonable subsidies, introducing energy-efficiency evaluation standards, increasing R\&D activities, etc. ${ }^{405}$ Most of the parties underscored

398 Unfccc, 'Second Synthesis Report on Technology Needs Identified by Parties Not Included in Annex I to the Convention' (2009) Note by the secretariat FCCC/sbSTA/ 2009/INF.1 28-30.

399 UnfCCC, 'Third Synthesis Report on Technology Needs Identified by Parties Not Included in Annex I to the Convention' (2013) Note by the secretariat FCCC/sBSTA/2013/ INF.7 25-27.

400 UNFCCC, 'Second Synthesis Report on Technology Needs Identified by Parties Not Included in Annex I to the Convention' (n 398) 28-30.

401 UNFCCC, 'Third Synthesis Report on Technology Needs Identified by Parties Not Included in Annex I to the Convention' (n 399) 25-27.

402 ibid 6, 25-26.

403 ibid 26.

404 UNFCCC, 'Second Synthesis Report on Technology Needs Identified by Parties Not Included in Annex I to the Convention' (n 398) 28-30.

405 ibid 30-31, 39-40. 
the need for financial incentives, commonly in the form of tax exemptions on imported technologies. The report further highlighted the need for detailed regulations and standards, technology information availability, also for facilitation of stakeholder networks to overcome policy, technical and network failures. ${ }^{406}$ The third report notes that some of the members indicate the need for further clarification of the relationship between intellectual property rights and technology transfer, but it was not registered as a significant barrier. 407

Recently, Sara Traerup and others prepared a report providing a comprehensive account of barriers and enablers for the technology executive committee (TEC). The report covers the TNA s made by the developing countries so far, their nationally determined contributions (NDC s), also technical assistance requests made by countries to the CTCN. ${ }^{408}$ The overall findings echo the conclusions above to a large extent. The authors find economic and financial barriers to be the single most significant hurdle for the least developed countries (LDC s) and the small island developing countries (SIDC s). ${ }^{409}$ A new finding was that the examined documents vary on the order of significance of other barriers. While the synthesis of information from the NDC $s$ and the CTCN requests show technical barriers to be the most significant category, ${ }^{410}$ the information from the TNA reports appear to put slightly more emphasis on policy and regulatory obstacles, as well as market imperfections. ${ }^{411}$ In the technical category, one key problem was poor quality, or performance of clean technologies, which the authors suggested to be tackled through appropriate standardisation initiatives. ${ }^{412}$ It was also noted that with respect to none of the desired technologies, economic and financial barriers were the only set of problems. This means that successful technology transfer would require a integrated, system-wide approach to overcome the existing problems.

406 UnfCCc, "Third Synthesis Report on Technology Needs Identified by Parties Not Included in Annex I to the Convention' (n 399) 28.

407 ibid 41.

408 Sara Traerup, L Greersen and C Kundsen, 'Mapping Barriers and Enabling Environments in Technology Needs Assessments, Nationally Determined Contributions, and Technical Assistance of the Climate Technology Centre and Network' (2018) Background paper $\operatorname{TEC} / 2018 / 17 / 4$.

409 ibid 7.

410 ibid 6, 9.

411 ibid 6-9.

412 ibid 5,15 . 
Box 2: Illustration of Barrier Analysis: TNA s of Moldova and Kenya ${ }^{413}$ The Republic of Moldova completed its TNA in 2012. In respect of the technology prioritised in the energy sector, i.e. combined heat and power generation using internal combustion engines (ICE CHP), the analysis indicated a range of economic, financial, and market-related barriers among others. It was indicated that the implementation of ICE CHP technology has a potential of G HG emission reduction of up to $24,415 \mathrm{tCO}_{2}$ by 2020. A key identified problem was high upfront cost of the technology, which meant that the economy of scale was achievable only on high investment levels. This was problematic due to small market size and high cost of finance. Also, there was no incentive (e.g. tax benefit, or pricing of negative externalities) in the markets for shifting to this technology. The barrier was further compounded by an absence of energy efficiency regulation and little experience of the regulating agency in this area. Moreover, some segments of the domestic market, i.e. district heating, were dominated by a few providers under an oligopolistic fashion. Measures planned by Moldova for overcoming the barriers included import duty exemption on the ICE C HP technology, energy efficiency regulation, optimisation of district heating market along with transparent cost allocation on heat and power, informational awareness and strengthening of the regulatory agency.

The barrier analysis done by Kenya in 2013 as a part of the TNA process, solar home systems (sHs) and solar dryers were identified as prioritised mitigation technology in the energy sector. The key problem in mainstreaming sHs technology was found to be prohibitive costs. Requirement of high upfront investment, cost of repair and maintenance, absence of any subsidies on the component prices, and high interest rates $(15 \%$ to $30 \%)$ charged on private loans, cumulatively prevented large scale deployment and diffusion of the technology. Issues that act as barriers to deployment of solar dryers were also found to be similar. Measures planned to remove those barriers in Kenya included steps to strengthen domestic regulatory institutions and standards, and creating linkages with internationally available support funds. Besides, corruption control was also identified as a necessary measure. Kenya planned to overcome supply and cost problems of the required technologies through setting up domestic manufacturing and assembling plants.

413 'TNA Country Reports' (TT:CLEAR)<https://unfccc.int/ttclear/tna/reports.html>accessed 25 October 2020. 


\section{Summary Analysis}

While not exhaustive, the growing body of empirical evidence on the barriers to low-carbon technology diffusion contains important insights that must be reflected in rulemaking and domestic policy formulations. We summarise those as follows -

a)

Low-Carbon Technology Diffusion Is a Developing Country-Specific Problem

Transfer of technology on commercial terms work well between partners who are equally well-off in terms of technical and financial capability. The largescale patent and license data surveys revealed that innovation and transfer of clean technologies is not a problem in the OECD member countries. In contrast, developing countries suffer a range of economic, financial, and technical barriers that prevent private commercial transactions from taking place. However, we find that some of the developing countries (especially, China, Korea, India, and Brazil) are increasingly changing this polarisation by catching up and leading the market in specific technologies.

b)

While Patent Protection Is Not an Apparent Major Problem, Further Clarification Is Desirable

So far, it can be said that a robust domestic system for the protection of intellectual property rights is one of the many factors positively influencing a foreign firm's propensity to transfer technology. Although patenting activity in clean technologies has surged over the recent decades, market competition and availability of alternatives in most sectors have prevented monopolies from arising. This is why the majority of scholarly opinions tend to favour the position that legal protection granted to intellectual property rights is a positive rather than a negative factor for the diffusion of low-carbon technologies. However, given the limited amount of studies, drawing general conclusions is difficult, also premature. To the extent information is available, no such obstacle has been found - especially in sectors where the technology is already commercially available. ${ }^{414}$ There is opportunity, and necessity too, to expand the scope of the studies focusing on the relationship between intellectual property rights and clean technologies, especially looking at issues of plant variety protection, or issues other than patents. ${ }^{415}$

\footnotetext{
414 See section III A above.

415 Bradly J Condon, 'Climate Change and Intellectual Property Rights for New Plant Varieties' (2013) 47 Journal of World Trade 897; Abdel-Latif (n 337) 115-116.
} 
c) Domestic and International Policies Should Target the Actual

Obstacles Faced by Private Firms

While IPR s are not found to pose significant obstacles in the different climate technology areas explored, sector or location-specific studies invariably find a significant positive impact of enabling policy frameworks that ease private firms' access and adoption of the technologies. In varying factual contexts, policy measures such as long-term guaranteed price, access to appropriate finance, local-content requirements, and energy efficiency regulations have been found to be beneficial. In addition, development of understanding and skills to adapt a new technological solution to local needs is important. Considering these aspects, the technology needs assessments (TNA s), and barriers identified in the process are of special relevance.

The available syntheses of the TNA reports overwhelmingly point to the economic and financial problems as the most significant barrier to climate technology diffusion. High prices, difficult financing, and little incentive in the market make technology adoption difficult. These problems are compounded by other issues like skills shortage, and absence of technical standards.

d) Market Development Is Very Important

The need for specific and coordinated attention to develop markets for clean technologies is undeniable. The highly shared view of pervasive economic and financial barriers as key obstacles are irrefutable indications of widespread market and system failure affecting climate technology dissemination. Studies therefore correctly highlight the need for medium to long-term policy interventions to tackle different forms of market failures. ${ }^{416}$ This is an important insight to carry on to the study of the trade rules, which, if allowed, can positively influence market formation by tackling some of the price barriers, and creating room for enahanced financial supports, as well as other incentives. ${ }^{417}$

The rest of this chapter focuses on tracing the current rules and related developments in the trade regime relevant for low-carbon technology diffusion.

\section{Developments in Trade Regulation}

References to technology transfer appear in the body of laws of the multilateral trade regime, and also in negotiations and deliberations from time to

416 See p. 79 above. Also in particular, Lybecker and Lohse ( $n$ 347).

417 This is discussed further in the next chapter. 
time. Concrete provisions regarding technology transfer only exist in the TRIPS agreement. Some provisions regarding technical assistance also appear in other areas of the WTO universe, but those are more tailored towards facilitating a specific objective. That apart, the WTO rules on removal of market access restrictions on trade in goods and services play a direct role in facilitating clean technology diffusion. In addition, one wTO working group is tasked with exploring the linkages between technology transfer and trade - a decades-long endeavour yet to bear fruit.

Beyond the boundaries of multilateralism, references to technological assistance and transfer of technology appears in some preferential trade agreements. Non-reciprocal unilateral preferences like the generalised system of preferences (GSP) and the Enabling Clause can also become of relevance as important routes to support the developing countries. Beyond the domain of the WTO, the UNCTAD is continuously engaged in research and communication in this area.

In the backdrop of the absence of any resounding success along the avenues mentioned above, recently transfer of technology has come up as a contentious point of dispute between key members. All these are discussed hereunder.

\section{A Existing Multilateral Rules}

The TRIPS Agreement

The wто Agreement on Trade-Related Aspects of Intellectual Property Rights (TRIPS) is a partial conclusion of the bargain between developed and developing countries that began in the NIEO context and led to the failed code of conduct. ${ }^{418}$ It has already been mentioned earlier in this chapter that transfer of technology is one of the objectives of the TRIPS agreement. It is also the subject of a strict obligation imposed on the developed countries for the benefit of the LDC s. Alongside, the TRIPS agreement emphasises the need to maintain effective competition regulations to prevent de facto monopolies as a result of the IPR protection.

Articles 7 and 8 elucidate the general approach taken in TRIPS towards technology transfer and its linkage with the protection of the IPR s. Article 7 contains an expectation that technology transfer is achieved through protection and enforcement of the IPR s. ${ }^{419}$ Following up, Article 8 recognises that additional measures may be required (e.g. competition regulation) to prevent

\footnotetext{
418 See the beginning of this chapter.

419 Article 7, Agreement on Trade-Related Aspects of Intellectual Property Rights (n 227). It holds that ' $[\mathrm{t}]$ he protection and enforcement of intellectual property rights should contribute to $[\ldots]$ the transfer and dissemination of technology $[\ldots]$ '.
} 
abuse of IPR s in ways that prevent technology transfer. ${ }^{420}$ It also mentions that public policy measures need to be consistent with the agreement. ${ }^{421}$ The general scheme therefore leads to the conclusion that in the absence of actions in pursuance of the obligation to transfer technology, protection of IPR $S$ is in itself a contribution to the facilitation of technology transfer.

However, the TRIPS agreement provides options, namely, reducing the scope of patent rights, or issuance of a license, which can be of use to further ensure technology diffusion. Articles 27 allows for exclusion of specific areas from the scope of patentability. Such exclusion can be for protection of public order or morality, ${ }^{422}$ or can cover therapeutic processes and plant varieties. ${ }^{423}$ The latter among those is only allowed subject to the condition that comparable alternate protection is put in place. Article 30 allows limitation of the exclusivity of patent rights subject to the condition that it does not 'unreasonably' interfere with the interests of the holder. Governments can, therefore, issue licenses without the authorisation of the patent holder to, inter alia, prevent anti-competitive practices. ${ }^{424}$ Under appropriate circumstances, these options can be of use to dismantle patent exclusivity related barriers to the diffusion of any technology.

Article 66.2 of TRIPS imposes a positive obligation upon developed countries to transfer technology in the following terms:

[...] Developed country Members shall provide incentives to enterprises and institutions in their territories for the purpose of promoting and encouraging technology transfer to least-developed country Members in order to enable them to create a sound and viable technological base. ${ }^{425}$

Although the provision uses strict obligatory language ('shall'), the subjectmatter of that obligation is not to transfer technology to the LDC s, but to provide incentives to domestic firms. The goal of such incentives is to 'promote and encourage' those firms to transfer technologies to the LDC s. Therefore, it can be questioned whether successful transfers of technologies from the developed countries to the LDC s are required to effectively discharge this obligation. More on this can be found in the following section.

\footnotetext{
420 Article 8.2, ibid.

421 Article 8.1, ibid.

422 Article 27.2, ibid.

423 Article 27.3, ibid.

424 Sub-paragraph (k) of Article 31, ibid.

425 Article 66.2 ibid.
} 

Other Relevant Rules under the Covered Agreements

Apart from the TRIPS agreement provisions carrying over some of the earlier political conflicts into the WTO, there are some other relevant commitments with respect to technological assistance, easing of market access and subsidisation. Assistance provisions mentioned here are of soft law nature, and therefore not capable to form the basis of a legal claim. More importantly, as these provisions are not exclusive to the LCT-related goods or services, they can be equally used to facilitate emission intensive trades as well.

\section{a) Rules for Easing Technology-Related Goods and Services Market Access}

Trade flows of LCT-embedded goods are directly dependent on the market access regulations in the General Agreement on Tariffs and Trade (GATT), especially those on tariffs. While all the wTо members are obliged to submit schedules containing maximum rates of tariffs, the levels mentioned therein are then subjected to multilateral negotiation rounds with a view to their gradual decrease. ${ }^{426}$ The negotiations are to be carried out with adequate consideration for the needs and situations of individual members and industries. ${ }^{427}$ It is also possible to reduce tariffs unilaterally, as long as the benefit is made equally available to all members.

In a similar fashion, market access regulation in the General Agreement on Trade in Services (GATS) is relevant to ensure that services that are integrated with LCT s are available domestically in competitive terms. For example, construction, engineering and consultancy services play a supportive role in renewable energy projects. Financial services are important to bridge the resource constraints faced by private firms interested in new technologies. Opening of a specific services sector is exclusively a member's prerogative, realised through positive commitments in its Schedule. ${ }^{428}$ Similar to the GATT, periodic negotiation rounds should take place to gradually increase effective market access on trade in services for all members, while according flexibility for the developing countries. ${ }^{429}$

The GATs further obliges the developed wTо members, also the developing members to establish contact points to facilitate information availability to the developing country suppliers. Information that is sought to be made easily

\footnotetext{
426 Article XXVIII bis, General Agreement on Tariffs and Trade 1994 (Marrakesh Agreement Establishing the World Trade Organization, Annex 1A, 1869 UnTS 299; 33 ILM 1197 (1994)).

427 Article XXVIII bis, ibid paragraph 3.

428 Articles XVI, and Xx, General Agreement on Trade in Services 1994 (Marrakesh Agreement Establishing the World Trade Organization, Annex 1B, 1869 UnTS 183; 33 ILM 1167 (1994)).

Article xx, ibid.
} 
available includes, among others, "the availability of services technology". 430 Special priority is provided to the least-developed countries (LDC s) in such facilitation effort.

\section{b) Provisions for Assistance Regarding Adoption of Green Standards}

To the extent that adoption of new technologies also involves conforming to technical regulations and standards, the Agreement of Technical Barriers to Trade (твт) comes in play. Article 11 of the твт agreement requires WTO members to advise and provide technical assistance to other members upon request, especially when such a request comes from a developing country member. The technical assistance is relating to different regulatory and compliance aspects of conformity assessment procedures between the countries, the establishment of standardising bodies, and participation in international standardising bodies. ${ }^{431}$ It is also provided that members shall encourage other bodies within their territories involved in conformity assessments to engage in similar advice and technical assistance. ${ }^{432}$ However developing country members are not expected to use international standards as a basis for domestic standard-setting, if such are not commensurate with their financial, developmental, or trade needs. ${ }^{433}$ Similar to above, the special needs of the LDC s are to be especially prioritised in this regard.

\section{c) Easier Subsidy Disciplines for Developing Countries}

The developing countries, especially the least-developed ones, can make use of the relaxed subsidy disciplines to support domestic firms' adoption of clean technology. The WTO agreement on subsidies (ASCM) does not prevent LDC s from export subsidisation. ${ }^{434}$ While the developing countries are supposed to phase out prohibited subsidies eventually, some may be maintained on justified grounds subject to review by the subsidies committee. ${ }^{435}$ Also, subsidies below a de minimis level by the developing countries shall not be countervailed. ${ }^{436}$

\footnotetext{
430 Article IV.2(c), ibid.

431 Articles 11.2 - 11.6, Agreement on Technical Barriers to Trade 1994 (Marrakesh Agreement Establishing the World Trade Organization, Annex 1A, 1868 UnTS 120).

432 Article 11.7, ibid.

433 Article 12.4, ibid.

434 Article 27.2(a) and Annex viI, Agreement on Subsidies and Countervailing Measures 1994 (Marrakesh Agreement Establishing the World Trade Organization, Annex 1A, 1869 UNTS 14).

435 Article 27.4, ibid.

436 Article 27.10, ibid.
} 
Also relevant to note in this regard is the lapse of non-actionable subsidies under the SCM agreement. Article 8 of the ASCM was drafted to keep three broad categories of domestic subsidies beyond scrutiny at the WTO - namely (i) subsidies for research and development, ${ }^{437}$ (ii) subsidies for the development of disadvantaged regions, ${ }^{438}$ and most importantly (iii) subsidies for compliance with environmental requirements. ${ }^{439}$ Each category had to comply with specific threshold limitations to be considered as non-actionable. The disagreements over the continuation of these supports resulted into the dismantling of non-actionable subsidies in $1999 .{ }^{440}$

Similar support measures remain available to members with respect to agricultural products. While Article 6 of the Agreement on Agriculture ensures that a member's aggregate amount of domestic support stay within committed levels, ${ }^{441}$ Annex 2 lays out some of the exemptions accorded to public services and programs in this regard, as long as those are not de facto price supports. Included in that scheme are government services, including environmental research related to agriculture, training services, extension and advisory services to transfer the knowledge gained from research. ${ }^{442}$ These options can be used to domestically explore and promote ways of less emission intensive farming methods. However, like most other provisions discussed, these are also general in nature.

\section{B}

\section{Negotiations and Deliberations at the WTO and UNCTAD}

The TRIPS Council is the body responsible for the administration of TRIPS agreement. In 2003, it was decided at the Council that the developed members will be required to report periodically on steps taken to implement Article 66.2 of the agreement. ${ }^{443}$ Pursuant to the decision, a number of the developed members have been reporting ${ }^{444}$ on the incentives granted by them. Already

\footnotetext{
437 Article 8.2(a), ibid.

438 Article 8.2(b), ibid.

439 Article 8.2(c), ibid.

440 For details, see, Dominic Coppens, WTO Disciplines on Subsidies and Countervailing Measures: Balancing Policy Space and Legal Constraints (Cambridge University Press 2014) 187-189.

441 Article 6.1, Agreement on Agriculture 1994 (Marrakesh Agreement Establishing the World Trade Organization, Annex 1A, 1867 UnTS 410).

442 Annex 2, para 2, ibid.

443 World Trade Organization, 'Implementation of Article 66.2 of the TRIPS Agreement: Decision of the Council for TRIPS of 19 February 2003' (2003) IP/C/28.

444 Every third year, new reports are submitted which are then reviewed and discussed in question and answer sessions.
} 
in 2011, Moon demonstrated the difficulty to measure how much technology transfer actually took place due to the TRIPS provision. The scope of the reports has remained ambiguous due to the absence of a common understanding of what technology transfer actually meant. There was also no specificity as to how a transfer is taking place. ${ }^{445}$ Later, while tracing the development up till 2016, Watal and Caminero reemphasised on the absence of a shared understanding, as well as found shortcomings in the conduct of both the developed and the LDC members. ${ }^{446}$ On developed countries' front, it was noted that the reports were often compiled from data obtained from different agencies, which appeared to be a recapitulation of the countries' official development assistance (ODA) activities. The authors argued further that a reason behind there not being a meaningful development in reporting is the lack of engagement from the LDC side in the question and response sessions that follow the reports. Authors conclude that "[m] eaningfully improving Article 66.2 implementation and reporting requires continuous and effective engagement of the part of both developed country and LDC member delegations". ${ }^{47}$

The reports submitted since the above assessment ${ }^{448}$ show that most members' reports lump a broad range of aid and support activities into technology transfer. To give a sense of how varied the items reported can be, the recent reports included mentions of training events, scholarship programs, specific financed projects, donation to international funds, and etc. One important noticeable issue however is that due to the broad range of activities reported, most are matters that bear no relationship with intellectual property protection at all. This is a consistent subsequent practice, which has given the legal meaning of Article 66.2 a scope that goes beyond the subject-matter limit of the TRIPS. The reports reviewed also show that countries frequently mention climate change related projects, e.g. those for renewable energy generation, as technology transfer incentives.

In a proposal to enable effective implementation of the technology transfer commitment, the LDC group requested the TRIPS council to deliberate and

445 Suerie Moon, Meaningful Technology Transfer to the LDCs: A Proposal for a Monitoring Mechanism for TRIPS Article 66.2 (International Centre for Trade and Sustainable Development (ICTSD) 2011).

446 Jayashree Watal and Leticia Caminero, 'Least-Developed Countries, Transfer of Technology and the TRIPS Agreement' (World Trade Organization 2018) WTO Staff Working Paper ERSD-2018-O1. The paper also contains a succint account of the evolution of Article 66.2 monitoring mechanism.

447 ibid 25 .

448 Latest sets of reports, submitted in 2015 (IP/C/w/611/Add.1-6) and 2018 (IP/C/W/646/ Add.1-6), were consulted for this purpose. 
decide that the developed countries should only report incentives that are extended to the LDC s for technology transfer. ${ }^{449}$ Moreover, the LDC group proposal also called for deliberation on the language, "incentives to enterprises and institutions", as found in Article 66.2.

The Committee on Trade and Environment (CTE and CTESS)

Established in parallel with the wTO itself, 450 the committee on trade and environment has become the hub to share information and deliberate on the trade and environmental issues in general, including issues involving trade and climate change. The regular sessions of the committee serves as a platform to deliberate on a range of matters, in the forefront being the Doha issues (i) market access impact of environmental measures, including possible economic and environmental benefit of lowering trade restrictions, (ii) relevant provisions of the TRIPS agreement, (iii) labelling requirements for environmental purposes, (iv) issues of technical assistance, and (v) environmental and developmental aspects of the negotiations. The committee is periodically briefed by the Wто members on various environmental issues, as well as international organisations. The UNFCCC has since long been an observer at the committee.

A key contribution of the CTE to attain trade and climate coherence is ensuring transparency through making information available. By the CTE authorisation, the што secretariat periodically publishes an updated environmental database, collecting and sorting all the environmental notifications in the wто. The database is informative regarding the the frequency and nature of climate change related regulations notified to the WTO, although a clear classification is not maintained. Another important contribution is a periodic publication of a matrix of environmental provisions that bear upon trade. The latest version takes account of the Paris Agreement. ${ }^{451}$

Since 2010, the deliberation and briefing activity of the CтE, within the scope of the above-mentioned mandate, has encountered issues that bear upon climate change. Member representatives of the 'friends of the fossil fuel reform' group have kept the committee abreast of the efforts being made in

449 World Trade Organization, 'Proposal on the Implementation of Article 66.2 of the TRIPS Agreement: Communication from Cambodia on Behalf of the LDC Group' (2018) IP/C/ $\mathrm{w} / 640$.

$45^{\circ}$ Uruguay Round ministerial decision on trade and environment, 15 April 1994.

451 wто Secretariat, 'Matrix on Trade-Related Measures Pursuant to Selected Multilateral Environmental Agreements' (World Trade Organization 2017) Note by the Secretariat WT / $\mathrm{CTE} / \mathrm{W} / 160 /$ Rev.8; TN/TE/s/5/Rev.6 134-149. 
cutting down unreasonable fossil fuel subsidies. There has been a consistent discussion of accounting and implementation methods of carbon footprinting, including a recent briefing on the ISO 14067 standard. ${ }^{452}$ Members were also informed on the progress of the plurilateral environmental goods agreement negotiation. ${ }^{453}$ Country experiences regarding trade and climate change interrelationships, trade components of respective NDCs were also shared. The UNFCCC also kept the members periodically updated on the progress of the climate negotiations. ${ }^{454}$

The discussion in the regular sessions of the CTE also outlines the hardlined divergence of views amongst members. For example, with respect to information briefs regarding the removal of fossil fuel subsidies, it was viewed by some as beyond the scope of the committee. ${ }^{455} \mathrm{~A}$ similar view is also shared by some members regarding discussions on climate-related issues, holding that it is of exclusive UNFCCC domain. ${ }^{456}$ This position also affected a recent proposal on deepening the understanding of trade and climate relationship. 457 Some others objected to the focus of the platform becoming almost exclusively climate-related. ${ }^{458}$ Members' supplied updates on the progress of the plurilateral environmental goods agreement (EGA) was also treated by some as being information only, and criticised by some for breaking out from the multilateral

$45^{2}$ Committee on Trade and Environment, 'Report of the Meeting Held on 20 June 2017: Note by the Secretariat' (World Trade Organization (WTO) 2017) Wт/Сте / / /63 16.

453 Committee on Trade and Environment, 'Report (2015) of the Committee on Trade and Environment' (World Trade Organization (WTO) 2015) WT/CTE/22 4-5.

454 ibid 5 .

455 It is a consistent position maintained by Saudi Arabia and Venezuela. See, Committee on Trade and Environment, 'Report of the Meeting Held on 28 June 2018: Note by the Secretariat' (World Trade Organization (WTO) 2018) WT/CTE/M/65 5; Committee on Trade and Environment, 'Report of the Meeting Held on 1 November 2017: Note by the Secretariat' (World Trade Organization (wто) 2018) Wт/СтE/M/64 4; Committee on Trade and Environment, 'Report of the Meeting Held on 20 June 2017: Note by the Secretariat' (n 452) 3; Also supported by Qatar, Committee on Trade and Environment, 'Report of the Meeting Held on 14 and 15 November 2016: Note by the Secretariat' (World Trade Organization (WTO) 2017) WT/CTE/M/62.

456 Position held by Saudi Arabia, Russian Federation and Venzuela over recent years, Committee on Trade and Environment, 'Report of the Meeting Held on 28 June 2018: Note by the Secretariat' ibid 14; Committee on Trade and Environment, 'Report of the Meeting Held on 20 June 2017: Note by the Secretariat' (n 452) 26-27.

457 Committee on Trade and Environment, 'Report of the Meeting Held on 14 and 15 November 2016: Note by the Secretariat' (n 455) 19-20.

$45^{8}$ View of Morocco and Bolivia, Committee on Trade and Environment, 'Report of the Meeting Held on 30 June 2016: Note by the Secretariat' (World Trade Organization (WTO) 2016) WT/Сте/M/61 25-26. 
platform. ${ }^{459}$ The Iso standard on carbon footprint was challenged on grounds of being undemocratic, not differential enough, and a trade barrier for developing country interests. ${ }^{460}$

The negotiation agenda mandated by Article 31 of the Doha declaration was pursued by the wTо members in the special sessions of the СтE. The mandate included negotiation in three areas - (i) relationship between the trade obligations and trade-related commitments in the MEA s, (ii) institutional coordination between the WTO and the MEA s, and (iii) reduction of tariff and nontariff barriers to trade in environmental goods and services. Over the last two decades, none of the three avenues has resulted in fruition. Developments in policy and jurisprudential approaches in recent times have made the necessity of negotiated rules for trade and environment harmonisation largely redundant. ${ }^{461}$ For example, the commendable jurisprudential approach by the Appellate Body has contributed to creating a level of certainty about the expected consequences of environment-conscious trade measures. Also, to the extent trade and climate change institutional coordination is concerned, ad hoc approaches have developed, and each institutions is granted observer status in relevant proceedings of the other. However, it is true that neither of the organisation can influence the other's agenda-setting. On the third avenue, the latest available unclassified information (from 2011) suggest deep divides lingering between developed and developing members on the scope of negotiation, and approach to be followed (i.e. list based, project-based, hybrid, or request and offer system) ${ }^{462}$ The difficulty of arriving at a multilateral consensus has seen in 2014 the triggering of a plurilateral approach. Though such a breakout signifies stronger ambition on the part of some members, reports and comments thereupon in the regular session suggest that the initiative also resulted in a possible lack of engagement by those members in the multilateral process. ${ }^{463}$ The issue remains hamstrung to this day.

459 View shared by Bolivia, Argentina, India and Cuba, ibid 34; Committee on Trade and Environment, 'Report of the Meeting Held on 6 October 2015: Note by the Secretariate' (World Trade Organization (WTO) 2016) WT/СTE/M/6o 18.

460 Committee on Trade and Environment, 'Report of the Meeting Held on 20 June 2017: Note by the Secretariat' (n 452) $16-17$.

461 Cossy and Marceau (n 92) 391.

462 Committee on Trade and Environment in Special Session (ctess), 'Report by the Chairman, Ambassador Manuel A. J. Teehankee, to the Trade Negotiations Committee' (World Trade Organization (WTO) 2011) TN/TE/2O 2-3, 15-17. According to the Chairman, '[t]he primary area requiring delegations' urgent attention relates to agreeing on an approach to coverage'.

463 Committee on Trade and Environment, 'Report of the Meeting Held on 6 October 2015: Note by the Secretariate' (n 459) 18; Committee on Trade and Environment, 'Report 


$$
\text { The Working Group on Trade and Technology Transfer (WGTTT) }
$$

The working group was established in response to the need felt by the developing countries, ${ }^{464}$ including the LDC s $^{465}$ for a common platform to clarify and implement the special and differential treatment provisions. Unlike the LDC s in the TRIPS council, there was no WTO forum where the developing countries could discuss the need for technology transfer. Nor was there any similar incentive schemes like that of the TRIPS Article 66.2. Prior to the Doha Ministerial Conference in 2001, a large number of developing countries voiced the desire to establish a work program on the issue. ${ }^{466}$ In response, the Doha Ministerial Declaration established the WGTTT with a mandate to examine the relationship between trade and technology transfer, also to make possible recommendations to increase technology flow to the developing countries. ${ }^{467}$ The Hong Kong Ministerial later provided a rolling mandate to continue work in the group. ${ }^{468}$

The exploratory part of the WGTTT mandate involved hearing from various international organisations engaged in the area and side by side sharing of members' experiences regarding technology transfer. Over the past decade and more, the group heard many presentations and briefings from all the major international organisations. ${ }^{469}$ Issues the WGTTT deliberated upon as a result of the briefings included the impact of home country measures, or taxation policies on technology transfer, trends of cross-border technology flow,

of the Meeting Held on 30 June 2016: Note by the Secretariat' (n 458) 35. This view is expressed by Venzuela, Argenta, India, Cuba and Bolivia during 2015 and 2016 meetings.

464 The earliest request was made by India, prior to the Seattle Ministerial Conference. 'Preparations for the 1999 Ministerial Conference: Communication from India' (General Council, WTO 1999) WT/GC/W/352.

465 Committee on Trade and Development, 'Proposed Work Programme for the Year 2000: Communication from Zambia' (World Trade Organization (WTO) 2000) WT/ сомтр/w/67; Committee on Trade and Development, 'Proposal for Sub-Committee Work Programme: Communication from Zambia' (Committee on Trade and Development, WTO 2001) WT/COMTD/LDC/W/24.

466 'Preparations for the Fourth Session of the Ministerial Conference: Communication from Cuba, Dominican Republic, Honduras, India, Indonesia, Kenya, Malaysia, Pakistan, Sri Lanka, Tanzania, Uganda and Zimbabwe' (General Council, wTO 2001) WT/GC/w/443.

467 Paragraph 37, 'Doha Ministerial Declaration' (n 93). It provided, '[w]e agree to an examination [...] of the relationship between trade and transfer of technology, and of any possible recommendations on steps that might be taken within the mandate of the WTO to increase flows of technology to developing countries'.

468 Paragraph 43, 'Doha Work Programme: Ministerial Declaration' (wTO 2005) WT/MIN(05)/ DEC.

469 Institutions that shared research findings with the group included, inter alia, UNCTAD, UNIDO, FAO, WIPO, OECD, and the World Bank. 
non-equity modes of technology transfer, different sector-specific studies, the role of global value chains, technology diffusion in developing countries, and more. Experiences were also shared by many member countries, including the European Union, Switzerland, the Philippines, and Chinese Taipei. However, the absence of a structure or a progressive work plan kept the discussions very broad, and ultimately no specific insight emerged. Somewhat similar to the earlier mentioned experience in the TRIPS context, there was no agreed understanding of what technology transfer was, or how it would be best assisted within the Wто mandate. Not only was the topic itself complex, but also arguably the inputs received by the working group from different institutional bodies were probably not based on the same understanding of the concept of technology transfer and its many dimensions.

Nonetheless, several common issues could be identified among the whole range of inputs received by the working group. Technological capacity and ability to innovate was universally accepted to be a significant contributor to increased factor productivity and therefore economic growth. Liberal trade regime, especially the import regime facilitating the acquisition of capital goods and intermediates were considered to boost access to technology. ${ }^{470}$ Both home and host country incentives to facilitate foreign direct investment (FDI) flows, especially in R\&D collaboration is also beneficial. ${ }^{471}$ Among others, effective IPR regimes, mobility of scientific and technical professionals, linkage of domestic business and industry associations to international networks and overall integration of innovation to government policy framework was also generally suggested. ${ }^{472}$ Not surprisingly, such insights are also in line with the empirical findings of the previous section.

The recommendations part of the working group's mandate fell short, as members' views on the topic did not coalesce enough to generate shared

470 As early as 2008, research findings shared by the World Bank contained these conclusions. WGTtT, 'Report (2008) of the Working Group on Trade and Transfer of Technology to the General Council' (World Trade Organization (WTO) 2008) WT/WGTTT/10; World Bank, Global Economic Prospects 2008: Technology Diffusion in the Developing World (The World Bank 2008) <http://elibrary.worldbank.org/doi/book/10.1596/978-o-8213-7365-1> accessed 25 October 2020.

471 WGTTT, 'Report (2004) of the Working Group on Trade and Transfer of Technology to the General Council' (World Trade Organization (WTO) 2004) WT/WGTTT/ 6 .

472 WGTTT, 'Report (2007) of the Working Group on Trade and Transfer of Technology to the General Council' (World Trade Organization (WTO) 2007) WT/WG TTT/9; WGTTT, 'Report (2010) of the Working Group on Trade and Transfer of Technology to the General Council' (World Trade Organization (WTO) 2010) WT/WGTtT/12; WGTTT, 'Report (2014) of the Working Group on Trade and Transfer of Technology to the General Council' (World Trade Organization (WTO) 2014) WT/WGTTT/16. 
conclusions. From the very beginning, the developing countries' interests converged around several issues, which include - a substantive review of technical support provisions in different WTO covered agreements, constraints in further implementation of those, and full operationalisation of the Article 66.2 of the TRIPS agreement. ${ }^{473}$ Progress in any of those areas was impossible due to several objections. ${ }^{474}$ In particular, it was contended that the review activities would result in substantive overlaps with other forum mandates, e.g. that of the TRIPS council. ${ }^{475}$ It was also argued that the WGTTT did not have a mandate to negotiate, which was necessary to review existing regulations. ${ }^{476}$ Furthermore, some claimed that any recommendation should have an organic linkage with work done under the exploratory part of the mandate. ${ }^{477}$ It is assumed that since no headway could be made towards progress, general interest in the group's activity waned over time. Only one recommendation has so far has managed to stay on the agenda, which is about development of a webpage meant to serve as a repository of technologies reasonably available and also to assist business to business matchmaking.

In 2018, the African group proposed a revision of the WGTTT mandate. ${ }^{478}$ The proposal sought for concrete tasks to be mentioned, e.g. assessment of developing country needs and constraints, examination of relevant WTO provisions, studying of appropriate incentives in a similar fashion to Article 66.2 of the TRIP s, and more. Although potentially useful for low-carbon technology diffusion, the success of the endeavour is subject to high speculation.

473 WGTtT,'Provisions RelatingtoTransferofTechnologyinwto Agreements:Communication from Cuba, Egypt, Honduras, India, Indonesia, Jamaica, Kenya, Mauritius, Pakistan and Zimbabwe' (World Trade Organization (WTO) 2002) WT/WGTTT/3/Rev.1; WGTTT, 'Possible Recommendation on Steps That Might Be Taken within the Mandate of the WTO to Increase Flows of Technology to Developing Countries: Communication from Cuba, India, Indonesia, Kenya, Pakistan, Tanzania and Zimbabwe' (World Trade Organization (WTO) 2003) WT/WGTTT/W/6.

474 WGTtT, 'Report (2004) of the Working Group on Trade and Transfer of Technology to the General Council' (n 473) para 8; wGTTT, 'Note on the Meeting of 19 July 2004' (World Trade Organization (WTO) 2004) WT/WGTTT/M/9 para 4; WGTTT, 'Report (2005) of the Working Group on Trade and Transfer of Technology to the General Council' (World Trade Organization (WTO) 2005) WT/WGTTT/7 paras 9, 11; WGTTT, 'Report (2008) of the Working Group on Trade and Transfer of Technology to the General Council' (n 470) paras 22, 24; WGTTT, 'Report (2010) of the Working Group on Trade and Transfer of Technology to the General Council' (n 472 ) para 33.

475 ibid.

476 ibid.

477 ibid.

478 WGTtT, 'Report (2018) of the Working Group on Trade and Transfer of Technology to the General Council' (World Trade Organization (WTO) 2018) WT/WGTTT/2o para 3.3-3.4. 
At the end of the day, the WGTTT remains an ideal platform to initiate the discussion as to which of diverse policy options to trigger low-carbon technology diffusion, would fall squarely in the WTO domain, how to prioritise those, and find the points of convergence among the members' interests to implement them in a positive, and inclusive manner.

Developments at the UNCTAD

Although the earlier UNCTAD efforts to establish a Code of Conduct on technology transfer practices failed to succeed, the experience gathered therefrom by states was influential to secure the technology transfer obligation enshrined in Article 66.2 of the TRIPS agreement. Since then, work related to transfer of technology at UNCTAD has produced a number of studies and reports, though none exclusively on climate technologies. Issues addressed in this regard include examination of different approaches in investment agreements to ensure transfer of technology, ${ }^{479}$ survey of home country measures, ${ }^{480}$ and communication of successful country experiences ${ }^{481}$. A range of industry and country-specific case studies was also published. ${ }^{482}$ Many of these reports were also presented at the WGTTT. Current mandate of UNCTAD includes, among other areas, continuation of research on the impact of transfer of technology on trade and development. ${ }^{483}$

In 2014, one UNCTAD report made a general survey of issues relating to transfer of technology and development. The report highlighted many existing gaps in knowledge, including the lack of a common definition of 'technology' or 'technology transfer.'484 The report also mentioned that despite a widening technology gap between the developed countries and the LDC s, ${ }^{485}$ a complete understanding of the policies necessary to close the gap remains wanting. 486 The concept of national innovation system, portraying the need for policy

\footnotetext{
479 UnCtAD, 'Transfer of Technology' (UnCtAD 2001) UnCtAD/ITE/IIT/28.

48 o UnCTAD, 'Facilitating Transfer of Technology to Developing Countries: A Survey of Home-Country Measures' (UNCTAD 2004) UNCTAD/ITE/IPC/2004/5.

481 UnCTAD, 'Investment and Technology Policies for Competitiveness: Review of Successful Country Experiences' (UNCTAD 2003) UNCTAD/ITE/IPC/2003/2.

482 UNCTAD, 'Studies in Technology Transfer: Selected Cases from Argentina, China, South Africa and Taiwan Province of China' (UNCTAD 2014) UnCTAD/DTL/STICT/2013/7; UNCTAD, 'A Case Study of the Salmon Industry in Chile' (UNCTAD 2006) UNCTAD/ITE/IIT/ 2005/12.

483 Paragraph 65(c) ‘UNCTAD XIII: Doha Mandate' (UNCTAD 2012) UnCTAD/ISS/2012/1.

484 unctad, 'Transfer of Technology and Knowledge Sharing for Development - Science, Technology and Innovation Issues for Developing Countries' (n 69) 2-3.

485 ibid $13-14$.

486 ibid 5 .
} 
interventions tackling market and system failures was also comprised in the report. ${ }^{487}$ It was further advised that the developing countries should make prudent use of the IPR flexibilities in the TRIPS agreement. ${ }^{488}$

\section{Trade Disputes Regarding Technology Transfer and Renewables}

Until recently, technology transfer has not been a contested issue in the vibrant history of Wто dispute settlement. There was one reference to it in the Appellate Body decision in the US - Shrimp dispute, ${ }^{489}$ where several countries challenged the United States (US) measure of prohibiting the import of shrimp caught in a process that incidentally harms sea turtles. In a landmark judgment, the Appellate Body in that dispute decided that the US measure was provisionally justifiable because endangered sea turtles were exhaustible natural resource and their conservation attempts a valid policy motive to maintain a GATT-inconsistent measure under Article Xx $(\mathrm{g})$ of the agreement. However, for any such measure to pass muster, its implementation needed also to be proven as not being arbitrary or unjustifiably discriminatory. The US measure failed that test regarding its varying technology transfer support. The Appellate Body considered that the level of effort made by the US to transfer necessary fishing technology to exclude turtles was connected to the duration of the phase-in period. As those periods were different for the members affected, the $\mathrm{AB}$ concluded that the level of effort made for necessary technology transfer was not the same. ${ }^{490}$

It is also relevant to not that trade remedy measures adopted by the developed countries regarding renewable energy production components have become frequent over the past decade. ${ }^{491}$ Spearheading these activities are antidumping $(\mathrm{AD}$ ) and countervailing ( $\mathrm{CVD}$ ) duties imposed by the EU and the US against Chinese solar cells and modules. ${ }^{492}$ Massive public funding leading to an exponential rise of the Chinese producers to the forefront of the global

487 ibid $22-23$.

488 ibid $28-29$.

489 United States - Import Prohibition of Certain Shrimp and Shrimp Products (n 94).

490 ibid 157.

491 Johannes Kasteng, 'Trade Remedies on Clean Energy: A New Trend in Need of Multilateral Initiatives' (International Centre for Trade and Sustainable Development (ICTSD), World Economic Forum (WEF) 2013); Kim Kampel, 'Options for Disciplining the Use of Trade Remedies in Clean Energy Technologies' (International Centre for Trade and Sustainable Development (ICTSD), World Economic Forum (WEF) 2017) Issue paper.

492 Kampel, ibid 12-17; Edwin Vermulst and Madison Meng, 'Dumping and Subsidy Issues in the Renewable Energy Sector' in Thomas Cottier and Ilaria Espa (eds), International Trade in Sustainable Electricity: Regulatory Challenges in International Economic Law (Cambridge University Press 2017). 
solar market ${ }^{493}$ has led to other countries scrambling to protect their domestic firms. Treatment of China as a non-market economy (NME) has also contributed to finding higher margins of dumping. ${ }^{494}$ While some of the antidumping disputes were settled through price undertaking, ${ }^{495}$ one challenge by China to the imposition of CVD by the US has made its way to the multilateral dispute settlement. ${ }^{496}$ Recently, the Republic of Korea challenged the imposition of safeguard duties by the United States on its exports of silicon photovoltaic products. ${ }^{497}$ China, facing similar US measures, also followed suit. ${ }^{498}$ Respective Panels have already been composed to hear the disputes.

It would be useful to note that trade remedy actions usually take place between countries that are competitive with each other in a given sector. Therefore, despite having a negative impact on the volume of trade, these disputes would have little impact on the flow of clean technology to new recipients. For example, during the same period as above, India also undertook an antidumping investigation and found a positive dumping margin regarding Chinese solar components exports, but no duties were imposed due to the domestic dependency on those products. ${ }^{499}$

In addition to above, past years also saw several wTO disputes where domestic subsidies coupled with local content requirements were challenged. Earliest among those was the Canada - Renewable Energy dispute, which led to some pathbreaking jurisprudence to be discussed later. ${ }^{500}$ Similarly, China

493 Zhang and Gallagher (n 8o) 195, 199; Helm, Tannock and Iliev (n 343) 25-30.

494 Vermulst and Meng (n 492) 337-338; Kampel (n 491) 17, 46.

495 Vermulst and Meng (n 492) 345; Christoph Herrmann, Bruno Simma and Rudolf Streinz (eds), Trade Policy between Law, Diplomacy and Scholarship: Liber Amicorum in Memoriam Horst G. Krenzler (Springer 2015) 389; European Commission, 'Fact Sheet: The European Union's Measures Against Dumped and Subsidised Imports of Solar Panels from China' $<$ https://rade.ec.europa.eu/doclib/docs/2015/july/tradoc_153587.pdf> accessed 25 October 2020; The minimum price undertaking was withdrawn in September 2018, Becky Beetz, 'EU Officially Ends MIP for Chinese Solar Imports' [2018] pv magazine International <https://www.pv-magazine.com/2018/o8/31/eu-ends-mip-against-chinese/> accessed 25 October 2020.

496 United States - Countervailing Duty Measures on Certain Products from China [2015] Appellate Body Report WT/DS437/AB/R.

497 DS545, United States - Safeguard measures on imports of crystalline photovoltaic products, request for consultations: 14 May 2018.

498 DS562, United States - Safeguard measure on imports of crystalline silicon photovoltaic products, request for consultations: 14 August 2018.

499 Vermulst and Meng (n 492) 346-347.

500 Canada-Certain Measures Affecting the Renewable Energy Generation Sector / CanadaMeasures Relating to the Feed-in Tariff Program [2013] Appellate Body Report WT/DS412/ $\mathrm{AB} / \mathrm{R} ; \mathrm{WT} / \mathrm{DS} 426 / \mathrm{AB} / \mathrm{R}, \mathrm{DSR} 2 \mathrm{O13}$ : I 7 . 
challenged some subsidy programs of EU member countries, which was settled at the consultation stage..$^{501}$ In 2016, as a result of US complaint, the Appellate Body confirmed a Panel decision holding that domestic content requirements in an Indian solar energy program as WTO-inconsistent. ${ }^{502}$ In response, India also successfully challenged similar requirements prevalent in the incentive schemes of seven states ${ }^{503}$ in the US. ${ }^{504}$ A similar challenge was also filed by China at the WTO, which has not progressed beyond the consultation phase. ${ }^{505}$

Since early 2018, transfer of technology has become a key sticking point in the relationship of the major trading partners with China. It has manifested in two separate claims eventually resulting in disputes - one complained by the United States, another by the European Union. In both cases, the claims challenge Chinese practice of what complainants term as 'forced technology transfer'. The practice in question involves Chinese requirement to enter into joint ventures, share technology, or perform researches in China in return of investment market access. These are some of the traits that academic literature discussed earlier found at times to be the reasons behind China's ability to swiftly scale up technological competence. ${ }^{506}$ In climate change literature, such use of domestic market access as leverage was taken as an example of successful strategy.

The US initiated its dispute (DS542) on 23 March 2018. The request for consultation circulated by the US indicates that the claim involves challenging a range of Chinese domestic regulations regarding import and export of technologies and equity joint ventures with foreign partners. ${ }^{507}$ It has been argued by the US that the laws in question limit the scope of a US patent holder's rights as guaranteed by Article 28 of the TRIPS Agreement. ${ }^{508}$ On 17 January 2019, a Panel has been composed to settle the dispute.

501 DS 452, European Union and certain Member States - Certain Measures Affecting the Renewable Energy Generation Sector, request for consultations 5 November 2012.

502 India-Certain Measures Relating to Solar Cells and Solar Modules (n 4).

503 Namely, Washington, California, Montana, Massachusetts, Connecticut, Michigan, Delaware, and Minnesota.

504 United States - Certain Measures Relating to the Renewable Energy Sector [2019] Panel Report WT/DS510/R.

505 DS 563, United States - Certain Measures Related to Renewable Energy, request for consultations 14 August 2018.

506 Lewis (n 371); Gallagher (n 71).

507 'China - Certain Measures Concerning the Protection of Intellectual Property Rights: Request for Consulatations by the United States' (2018) WT/DS542/1; IP/D/38.

508 Side by side, the United States has also taken unilateral retaliatory measures. Those are discussed addressed in Chapter 6 below. 
The EU launched its own dispute (DS549) against China in June 2018. This dispute challenged thirty-six specific pieces of domestic regulations in China. ${ }^{509}$ Among those, one exclusively relates to low-carbon technology, namely China's New Energy Vehicles (NEv) Production Enterprises, and Production Regulation. The European Union contended that the Chinese regulatory requirement upon foreign enterprises seeking to enter new energy vehicles market (including, electric hybrids and fuel cell operated vehicles) to, inter alia, master and understand the technology, establish exclusive design and development institution, and establish product information databases, including technical and design specifications is a violation of the commitment made by China in its Protocol of Accession to the wTO. ${ }^{510}$ The commitment in question is contained in paragraph 7.3 of Part I of the Chinese Protocol of Accession to the WTO. It precludes the country from imposing performance requirements upon foreign investments, which the EU alleges the Chinese technology transfer practices to violate.

\section{Non-Multilateral Approaches}

(i) Plurilateral Initiatives

a) Environmental Goods Negotiation

A plurilateral initiative to remove tariff barriers on an agreed list of environmental goods was launched in 2014. Although the initiative was welcomed as taking the process forward, subsequent CTE reports and meeting minutes indicate that some developing countries find such step as stalling the possibility of a multilateral solution. ${ }^{511}$ However, the plurilateral initiative itself stalled in 2016. Disagreement among parties on the list of products to be included was considered to be the main reason leading to the deadlock. ${ }^{512}$ While on the record, the parties remain committed to finding a solution, ongoing trade war and the US threat to the multilateral trade system have shifted the priorities. It does not seem plausible that the talks would restart any time soon.

Outside the domain of the wTо, however, twenty-one members of the AsiaPacific Economic Cooperation (APEC) have agreed in 2012 to a fifty-four items

509 'China - Certain Measures on the Transfer of Technology: Request for Consulatation by the European Union (Revision)' (n 4).

510 ibid 6.

511 See (n 459) above.

512 ICTSD, 'Ministerial Talks to Clinch Environmental Goods Agreement Hit Stumbling Block' (2016) 20 BRIDGES <https://ictsd.iisd.org/bridges-news/bridges/news/ministerial-talksto-clinch-environmental-goods-agreement-hit-stumbling > accessed 25 October 2020. 
list of environmental goods, tariffs upon which are to be gradually lowered to 5 per cent or less. ${ }^{513}$ The list covers products relating to renewable energy generation. However, in terms of low-carbon technology, the coverage is not comprehensive. ${ }^{514}$ Moreover, as the APEC is a voluntary forum, the commitments do not have a binding effect upon the participants.

\section{b) Provisions Allowing Green Public Procurement}

The plurilateral governmental procurement agreement (GPA) is in effect since 1994 among 48 WTO members with an aim to open up the government procurement market to the participants. While the GPA requires participants to issue technical specifications and select the most advantageous tender, the revised agreement further mentions that such specifications can be prepared to "promote the conservation of natural resources or protect the environment".515 This further clarifies the ability of a government participant to the revised GPA to choose low-carbon technologies compared to polluting but cheaper alternatives. Although so far there are only a handful of developing countries participating in the revised GPA, some remain in the process of accession and many others take part as observers.

\section{Preferential Trade Agreements (PTA s)}

According to one report, by 2016 there were thirty-four preferential trade agreements (PTA s) that have specific mention of climate change. ${ }^{516}$ To provide context for this number, the same research mentions that general references to the environment are made in 263 PTA s, including the 114 where specific

513 Annex C, '2012 Leaders' Declaration' <https://www.apec.org/Meeting-Papers/LeadersDeclarations/2012/2012_aelm> accessed 25 October.

514 Rene Vossenaar, 'Identifying Products with Climate and Development Benefits for an Environmental Goods Agreement' (ICTSD 2014) <https://seors.unfccc.int/applications/seors/attachments/get_attachment?code=FL5IRCXNKHGQDAD6JQULRT${ }_{67} \mathrm{~L}_{7} \mathrm{Ao2} \mathrm{OHU}>$ accessed 25 October $202 \mathrm{O}$.

515 Article $\mathrm{x}(6)$, Revised Agreement on Government Procurement 2012 (Marrakesh Agreement Establishing the World Trade Organization, Annex 4B, 1915 UnTS 103, (1994)); Marc Steiner, 'The WTO Government Procurement Agreement: Assessing the Scope for Green Procurement' (2015) 9 BIORES <https://ictsd.iisd.org/bridges-news/biores/overview? page $=6>$ accessed 25 October 2020; Robert D Anderson and Anna Caroline Muller, 'The Revised WTO Agreement On Government Procurement (GPA): Key Design Features and Significance for Global Trade and Development' 48 6o, 96o, 970-971.

516 José-Antonio Monteiro, 'Typology of Environment-Related Provisions in Regional Trade Agreements' (World Trade Organization 2016) WTO Staff Working Paper E RSD-2016-13 67. This is the number when explicit reference to climate change is taken into account. When indirect references are included, e.g. provisions on energy efficiency, or renewables, the author notes that the number goes up to 59 . 
environmental provisions can be found. ${ }^{517}$ Climate commitments found in the PTA s so far are of best endeavour nature - mostly involving reciprocal agreements to reduce emission, to cooperate on specific areas like renewable energy, or technological innovations, while allowing for flexibility to accommodate developing country interests. ${ }^{518}$ Some specific commitments exist with regard to the promotion of trade in environmental goods, services, and technologies. ${ }^{519}$ While the author of the aforementioned report does not specifically highlight it, a quick inspection reveals that most of the PTAs with climate change commitments are those in which the European Union is a party. These include the EU agreements with Colombia and Peru, Georgia, Moldova, Canada, Ukraine, South Korea, Turkey as well as association agreements with Macedonia, and Croatia. This is an example of the positive change a capable and willing country can induce unilaterally. Other significant agreements outside the EU partnership are the PTA s between South Korea and Peru, Japan and Peru, South Korea and New Zealand, as well as South Korea and Turkey.

The PTA between the EU, Peru and Colombia went the farthest in incorporating climate law notions within the agreement. Of special importance is the endorsement of common concern and a related duty to cooperate in the following terms:

[T] he Parties recognise that climate change is an issue of common and global concern that calls for the widest possible cooperation by all countries and their participation in an effective and appropriate international response, for the benefit of present and future generations of mankind. ${ }^{520}$

Against this backdrop, the above legal provision further iterates commitment to differentiated responsibility and equity. ${ }^{521}$ The parties articulate the objective

517 ibid 9 .

518 ibid 67 .

519 ibid $5^{6-57}$. Based on the author's computation of the data in the WTO RTA database, 17 agreements contain provisions on trade in renewable energy products and services. The same number for energy-efficient goods and services is 13 .

520 Article 275.1, 'Trade Agreement between the European Union and Its Member States, of the One Part, and Colombia and Peru, of the Other Part' [emphasis supplied].

521 Article 275.2 , ibid. It provides that ' $\mathrm{t}$ ] he Parties are resolved to enhance their efforts regarding climate change, which are led by developed countries, including through the promotion of domestic policies and suitable international initiatives to mitigate and to adapt to climate change, on the basis of equity and in accordance with their common but differentiated responsibilities and respective capabilities and their social and economic conditions, and taking particularly into account the needs, circumstances, and high vulnerability to the adverse effects of climate change of those Parties which are developing countries'. 
as being a rapid transition to low-carbon economies and further agree to promote trade and environment measures that would enhance access, dissemination and use of clean production technologies and the same for mitigation and adaptation. With respect to specific measures, the parties commit to consider steps that would contribute to mitigation and adaptation, including removing barriers to trade in goods and services in mitigation technologies as well as boosting energy efficiency and renewable energy.

In contrast, the United States, as a developed country and still the most powerful player in international trade, casts a strong negative shadow on climate and trade interaction. None of the PTA s to which the US is a party contain specific provisions referring to climate change, although many of them address environmental issues in a highly elaborate fashion. Nowhere is the absence more conspicuous than the recently negotiated USMCA. ${ }^{522}$ The environmental chapter of this agreement between the three North American trading partners covers many issues, without mentioning climate change even for once. It cannot but be a deliberate choice. There is also a similar absence of reference to climate change in the СРТРP, ${ }^{523}$ which in all probability can be attributed to the initial interest of the United States to get on board. This stance of the United States is a major obstacle in multilateralising any emerging positive PTA language.

It is noteworthy that neither China nor India is a party to any PTA s that is responsive to the need for trade and climate cooperation. This speaks of their conservative attitude when it comes to assuming greater responsibility. While India is less present in the PTA scene in general, its existing PTAs hardly contain any environmental commitment, hard or soft. The Chinese story is similar, although China has a range of preferential trade agreements, especially with the East Asian trading partners. Some of the Chinese PTA s mention environment with respect to the exception provisions. None of the two countries is a party to the mega-regional trade agreements. India, among the two still benefits from a few GSP schemes, ${ }^{524}$ preferences wherein are not currently conditional upon any climate-related preconditions.

522 Chapter 24, Agreement between the United States of America, the United Mexican States, and Canada (USMCA), Signed 30 November 2018 https://ustr.gov/trade-agreements/ free-trade-agreements/united-states-mexico-canada-agreement/agreement-between, accessed 25 October 2020.

523 Chapter 20, Comprehensive and Progressive Agreement for Trans-Pacific Partnership (СРTPP), entry into force 30 December 2018 https://www.mfat.govt.nz/assets/Tradeagreements/TPP/Text-ENGLISH/2O.-Environment-Chapter.pdf, accessed 25 October 2020.

524 The number of GSP donors for India stood at 8 in 2018. UnCTAD, Generalized System of Preferences: List of Beneficiaries (UNCTAD 2018). In March 2019 the USA decided to withdraw the GSP beneficiary status of India. 
In recent research, Morin and Jinnah have taken the analysis one step forward trying to answer the question as to what extent the merging of climate issues into PTA s accrue beneficial results. ${ }^{525}$ Analysing the climate change related provisions in 688 PTA s signed since 1947, the authors come to a sobering conclusion. One key finding is that despite the optimism surrounding preferential agreements serving as building blocks towards multilateral rules, the climate-related commitments, even when concrete, do not really add to the existing mitigation efforts. It is because there is no evidence suggesting that big emitters otherwise not committing to mitigation are doing so in a PTA. The authors guess that it is possibly due to the fact that countries consider long term climate costs are not balanced by the additional economic and political gain of economic integration. Another evidential finding is that climate-related commitments have increasingly become precise over time, especially in the 21st-century PTA s. However, there exists a trade-off between the precision of the commitments and the stringency of the enforcement provisions. The PTAs signed by the EU tend to have relatively detailed and precise commitments, but they are usually backed up with a consultation-based compliance mechanism. Whereas, those signed by the US contain very general climate commitment, but they tend to have stricter dispute settlement provisions often resulting in a binding determination.

\section{Conditional Unilateral Preferences: GSP s under the Enabling Clause}

The generalised system of preferences (GSP s) are unilateral preferential tariff schemes offered by a developed country to developing and least-developed ones. GSP schemes derogate from the standard non-discrimination commitment at the wTо. Such derogations are possible due to a decision by the GATT contracting parties, formalised in $1979 .{ }^{526}$ While the GSP can be used to grant special LCT-related tariff benefits to the developing countries, subject to adequate performance prerequisites, no such scheme has yet been put in place. One encouraging example is the EU practice, wherein benefits additional to the regular GSP scheme (named 'GSP plus') are accorded subject to the beneficiaries' participation in a select number of human rights, labour protection and environmental treaties, including the UNFCCC. ${ }^{527}$

525 Jean-Frédéric Morin and Sikina Jinnah, 'The Untapped Potential of Preferential Trade Agreements for Climate Governance' (2018) 27 Environmental Politics 541.

526 Differential and More Favourable Treatment: Reciprocity and Fuller Participation of Developing Countries 1979 (L/4903).

527 Annex VIII, Regulation (EU) No 978/2012 of the European Parliament and of the Council of 25 October 2012 applying a scheme of generalised tariff preferences 2012. 
a)

\section{The Polarised Legacy of Technology Transfer in a Hard Law Framework}

Although with respect to technology transfer, the trade and the climate regime started from a common position of the unsuccessful code negotiations, subsequent developments have been markedly different. While a soft-law based approach in the climate regime has led to an incremental formulation of an institutional structure with respect to clean technology development and transfer, no comparable development took place within the trade regime. One reason behind such different outcomes is that unlike the climate rules framework, negotiated rules in the trade regime entail strict legal consequences, resulting in a possible tendency among actors to avoid making of costly new rules. While there are many existing rules that are relevant for low-carbon technology diffusion, most are of general nature.

Yet another reason for the absence of progress in the wTо front is the inheritance of the politically fraught issue of technology transfer and protection of IPR $\mathrm{s}$ by the WTO. The TRIPS council is the ideal platform where the developing countries could voice concerns over necessary IPR flexibilities to facilitate technology transfer. This had the effect of drawing all the political capital, leaving little, or none to explore new avenues of technology diffusion.

b)

\section{Stalemate as the State of Play at the WTO}

Connected to the above, although the existing empirical studies showed that there is a need to influence the markets for greater diffusion of LCT s, any focused and meaningful discussion to that effect is yet to take place in the WTO. The absence of a common understanding of transfer of technology and its determinants have led to a compartmentalisation of discussions in different deliberative fora like the TRIPS council, the trade and environment committee, and the WGTTT, without any meaningful synergies being developed over time. We find some technical assistance and subsidy provision that may be of utility, but those remain of general and best endeavour character.

The deadlock in progress actually serves the members whose interests are vested in keeping the status quo. This is conspicuous from the repeated refusals to cooperate by some members at the CTE. To take the agenda of trade and LCT diffusion forward, this stalemate situation must be overcome.

\section{c) Limited Progress Made in Smaller Constellations}

Outside the што, there have indeed been somewhat successful attempts at liberalising environmental goods - some of which also cover LCT s. While in 
smaller constellations there are positive alignments of interests, in broader participatory groups, progress is stalled. Evidence of the former is visible in the PTA s where like-minded parties make detailed commitments going beyond the Wто standard. The latter can be noted in the stuck plurilateral negotiation on environmental goods.

\section{d) Improving Trade Cooperation for Clean Technology Diffusion Is Important}

In the backdrop of emerging disputes involving technology transfer, as well as growing political distrust, it is impossible to overemphasise the urgency of effective cooperation at the WTO in this regard. Cooperation will not only further the cause of LCT diffusion, but will also strengthen the institution's legitimacy.

The doctrine of Common Concern can supply the formal structure and normative content around which an effective convergence of interest of the WTO members is possible. By creating an exclusive dialogue around the need for effective trade-related responses to facilitate climate technology diffusion, the doctrine of Common Concern will attract the parties to engage in meaningful negotiation. This will be elaborated in the following chapter.

This chapter undertook an important stocktaking exercise. Beginning at the aftermath of the unsuccessful origin of technology transfer as an international agenda, it traced through the regulatory morphosis in the climate and the trade regime. It also presented a comprehensive picture of the existing literature on the determinants of low-carbon technology diffusion.

We found that transfer of technology only becomes a topic in public international law when commercial transactions at private market terms leave some or many actors dissatisfied, almost often involving developing country partners. This leads to general or issue-specific attempts, which at times successfully generate regulatory arrangements for desired levels of clean technology diffusion.

We also found that approaches to technology diffusion arrangements can vary a great deal across legal regimes. The climate regime showcases a multipronged approach. Despite an expansive framework based on a deeper understanding of the issue, the approach falls short due to its reliance on financial resources, which is unavailable at the required scales, and also due to its failure to agree on market reform approaches. Avenues in the trade regime remain less successful in striking a common understanding as to the meaning and scope 
of technology transfer. Efforts made in the trade regime tend to focus on the issue of intellectual property protection, which is of importance in many areas.

Review of the existing empirical studies indicated that legal protection of intellectual property rights is not a significant barrier for the diffusion of climate technologies. The studies rather highlighted a necessity to undertake market development policy measures, i.e. actions that would tackle the existing market failures in the dissemination of LCT s. The part trade rules can play in that regard remains yet to be explored. Moreover, political disagreements and conflicts of views, especially with regard to according a more active role to market reforms in the building up of enabling environments, was found to affect both trade and climate regimes. The outcome of such conflicting positions of countries is not only limited to the absence of adequate progress in rulemaking. It also fuels disputes in the trade regime.

One positive development that is noted, however, is the increasing recognition of the role of the trade policy measures for climate action, including diffusion of technologies in the PTA s. The EU appeared to play the most progressive role in this regard. 